\title{
Stuttering, Language, and Cognition: A Review and a Model of Stuttering as Suprasegmental Sentence Plan Alignment (SPA)
}

\author{
Rachel Karniol \\ Tel Aviv University
}

\begin{abstract}
Extant models of stuttering do not account for: the emergence of stuttering at the onset of productive language use; the greater incidence of stuttering during spontaneous speech, on complex sentences, and at sentence-initial positions; the greater incidence of stuttering in bilinguals' 2 nd language; the apparent deficiency of stutterers in expressive and receptive language skills; the prevalence of spontaneous recovery from stuttering; and the lack of chronic physiological or articulatory deficits in stuttering children's fluent speech. The author presents a model of stuttering as points of suprasegmental sentence plan alignment (SPA). Such alignment processes occur when, due to on-line sentence production processes, SPAs adopted prior to utterance initiation need to be aligned with revised SPAs. This model parsimoniously accounts for the findings reviewed in the article.
\end{abstract}

Stuttering involves disruptions in the flow of speech that are manifest as complete blocks, part-word or whole-word repetitions, and word elongations. Stuttering has been examined primarily by researchers in the field of speech pathology and motor control and has largely been ignored by psychologists. This state of affairs most likely stems from a belief that stuttering involves failures of motor processes of message transmission rather than failures of cognitive or linguistic processes of message generation (cf. Folkins, 1991). In a much cited review, Andrews and his colleagues ( 1983) exemplified this view. They defined stuttering as a disorder "in which the individual knows precisely what he wishes to say, but at the time is unable to say it because of involuntary, repetitive prolongation or cessation of sound" (p. 226). This definition removes the burden of stuttering from the cognitive or linguistic system and places it squarely on the motor system. Yet stuttering occurs in a unique pattern that cannot easily be accommodated within a motor framework or be attributed to a loss of control over speech physiology. Instead, the involvement of such motor processes may well be a symptom of stuttering rather than its cause (cf. Conture, 1991; Garber \& Siegel, 1982).

The purpose of this article is first to highlight findings that appear to implicate cognitive or linguistic processes in stuttering. I focus primarily on stuttering in children; stuttering is first manifest in childhood, and it is in that context that stuttering must be accounted for. I refer to the adult data only when they parallel the findings with children because any divergence from the childhood stuttering pattern can readily be explained as a syndrome of adaptation (cf. Garber \& Siegel, 1982; Kolk, 1991; Prins, 1991). I then relate the data to current models of stutter-

I thank Mike Ross of the University of Waterloo, Waterloo, Ontario, Canada, and Yossi Grodzinsky of Tel Aviv University, Ramat Aviv, Israel, for their helpful comments on previous versions of this article.

Correspondence concerning this article should be addressed to Rachel Karniol, Department of Psychology, Tel Aviv University, Ramat Aviv, Israel. ing and, finally, outline a model of stuttering to account for the pattern of findings.

Two methodological issues have important implications for my review. The first of these issues is how stutterers are identified; the second and related issue is that of sample size. In the majority of studies, stutterers are self-referred adults or parentreferred children who are either undergoing or awaiting therapeutic intervention. As in all clinical studies, the selection of an adequate control group then becomes critical. Control groups are seldom matched to stuttering groups by age, sex, or education. Consider a study by Zimmermann (1980) that is often cited as showing that, even when fluent, stutterers' utterances evidence different articulatory dynamics than the utterances of nonstutterers. In this study, a mixed-sex control group with a mean age of 26 years was compared with an all-male stuttering group with a mean age of 39 years. Consequently, any betweengroups differences can be attributed to age, sex, or both. Such confounds, which are quite prevalent in stuttering research, make it difficult to draw definitive conclusions about possible between-groups differences.

Most stuttering researchers use very small samples of subjects. When a within-group design is used, the problem of small sample size is not serious. However, when small sample size is coupled with nonsignificant differences between groups, it is difficult to know whether null results reflect a lack of power. Null results should therefore be interpreted with great caution; such caution is seldom evident in stuttering research. Conducting a review of stuttering is rendered quite difficult by these methodological issues. I have attempted to circumvent the problems occasioned by these issues by looking for studies that appear to be unconfounded and for groups of studies that have addressed the same research questions with parallel patterns of results. I start by reviewing the findings.

\section{Stuttering Onset and the Development of Productive Language Co-Occur}

Stuttering is "a disorder of early childhood" (Adams, 1982, p. 171). It is difficult to pinpoint the exact age of stuttering onset 
because a parent or a child-care professional must first become sufficiently attuned to the problem to refer the child to a speech pathologist. Consequently, there is always a lag between the point of stuttering onset and the point of referral. Granted this difficulty (see Nippold, 1990), the age of stuttering onset appears to be around 2 years, and, in the majority of cases, it occurs before the age of 3 years (Yairi, 1983).

The age of 2-3 years is well beyond the point of speech onset in most children. Crystal, Fletcher, and Garman (1976) placed the onset of single words at 9 months and the correct use of syntax in the fourth stage of language acquisition, which they identified as between the age of 30 and 36 months. Johnson (1955) found that the median interval between the first spoken words and the onset of stuttering was 23 months, again yielding a mean age of 32 months. This pattern is consistent with the conclusion that stuttering does not occur at the one-word or two-word stage ' (Eisenson, 1984; Karniol, 1992). The onset of stuttering generally occurs at the point in development at which children start incorporating the syntactic rules of their language in their productions (e.g., Brown, 1973; Slobin, 1970). In the only published case study documenting stuttering onset, Karniol (1992) found that stuttering began at 25 months, 12 months after speech onset. During this 12-month period, the child expressed over 200 fluent multiword utterances in two languages with no stutter or any disfluency being evident. Stuttering onset paralleled the emergence of productive use of syntactic rules in both languages. Developmentally, then, stuttering is related to producing sentences rather than to producing speech per se.

\section{Stuttering Is Primarily a Sentence-Level Phenomenon}

There are several different lines of evidence indicating that stuttering is primarily a sentence-level phenomenon. First, both adults and children who stutter in other speech contexts often evidence few disfluencies in producing single-word responses ${ }^{2}$ (Weiner, 1984; Wolk, 1990). Second, stuttering adults are more disfluent when producing the same words in sentence contexts than when producing the same words as part of a word list (Hamre \& Wingate, 1973) ${ }^{3}$ Third, fewer disfluencies are produced when the same word occurs in the identical location on repeated readings than when it occurs repeatedly in different locations within the same passage (Wingate, 1986). If stuttering were a word-level phenomenon, the rate of disfluency in producing a given word should be the same when the word is read twice within the same reading passage and when it is read for the second time on a repeated reading of the same passage. These convergent lines of evidence indicate that stuttering is primarily a sentence-level phenomenon.

\section{Stuttering Occurs Primarily on Sentence Production Tasks}

Stuttering is much more frequent on tasks that require both sentence formulation and overt speech than on overt speech tasks without the need for sentence formulation. This pattern has emerged in several kinds of studies, including ones in which some participants formulated their own utterances and others verbalized utterances provided by someone else. In one such study, Winkler and Ramig (1986) used a sentence-imitation and a story-retelling task with 6-12-year-old stuttering and nonstuttering children. They found that stuttering children differed from nonstuttering children on the spontaneous speech task but not on the sentence imitation task. This pattern is not unique to stuttering children; spontaneous speech is associated with more disfluencies in nonstuttering children as well (e.g., Gordon, Luper, \& Peterson, 1986). For instance, Gordon and Luper (1989) gave 3-, 5-, and 7-year-old nonstuttering children a modeling task, in which they heard a model sentence and had to produce another sentence using the same word order, and an imitation task, in which they had only to repeat a sentence provided by the experimenter. More disfluencies were produced on the modeling task than on the imitation task.

Studies comparing stuttering rates during spontaneous speech and reading have shown a similar pattern. Stuttering is generally less frequent during reading than during spontaneous speech (e.g., Johnson, 1961; Shapiro, 1980), with some stutterers evidencing almost no stuttering during reading, even though reading speed is about $25 \%$ faster than the speed of spontaneous speech (Johnson, 1961).

The consistent difference between spontaneous speech and reading also emerges in studies in which researchers experimentally manipulate when participants hear their own voice. This procedure, known as delayed auditory feedback (DAF), often reduces stuttering during reading but not during spontaneous speech (e.g., Hutchinson \& Norris, 1977; Ingham, Southwood, \& Hersburgh, 1981; Moore, 1978). Although the reasons for this difference are not clear, spontaneous speech, which requires sentence formulation, appears to be quite different from speech production per se.

Another line of evidence for the role of sentence production comes from studies testing the hypothesis that for stutterers, language production and motor programming interfere with each other (cf. Peters \& Starkweather, 1990). Such studies examine the effects of concurrent motor performance on stutterers' ability to formulate speech or to read aloud. The one study that examined this issue in children (Brutten \& Trotter, 1986) did not examine disfluency rates. With adults, the pattern is quite consistent, showing that conditions requiring speech formulation induce more disfluencies. For instance, Thompson (1985) had stuttering and nonstuttering participants describe Thematic Apperception Test (TAT) cards and recite nursery rhymes while concurrently performing two tracking tasks.

\footnotetext{
${ }^{1}$ One of the reviewers indicated that stuttering has in fact been heard at the one- and two-word stage in children of stuttering adults. This cannot, however, be taken as definitive unless it can be demonstrated that such children know the correct, unstuttered version of those words they emit in a disfluent fashion.

${ }^{2}$ As one of the reviewers pointed out, however, many nonstuttering and stuttering adults tend to produce difficult words in a disfluent fashion (e.g., statistics). However, this finding does not invalidate the general pattern I illustrate below.

${ }^{3}$ One could account for this finding by arguing that sentences are spoken faster than word lists, a point raised by one of the reviewers. As I indicate later, though, speed cannot be the relevant variable because although reading rate is much faster than spontaneous speech, it is nonetheless associated with significantly less stuttering than spontaneous speech.
} 
Tracking accuracy did not differ between groups. However, stutterers produced more disfluencies while describing TAT cards, a task requiring spontaneous speech; in contrast, nonstutterers' disfluencies did not differ for the two types of speech tasks. Similarly, Greiner, Fitzgerald, and Cooke (1986) required adult stutterers and nonstutterers to tap in sequence from index finger to little finger while engaged in silent reading, overt reading, singing, or spontaneous speech. Stutterers reduced their tapping rates and were significantly more disfluent than nonstutterers only during spontaneous speech. Across these different types of studies, then, the data consistently show that spontaneous speech tasks induce more stuttering and underline the conclusion that sentence formulation is clearly implicated in stuttering.

\section{Stuttering Is Related to Word Position in the Sentence}

In adults, stuttering is more likely to occur at the beginning of sentences, both in spontaneous speech (Koopmans, Slis, \& Rietveld, 1991) and in oral reading (Bloodstein \& Grossman, 1981; Quarrington, 1965; Quarrington, Conway, \& Siegel, 1962; Sheehan, 1974; F. H. Silverman \& Williams, 1967). Stuttering children also evidence this word-position effect (Wall, 1980; Williams, Silverman, \& Kools, 1969). For instance, Williams et al. ( 1969) found that stuttering children's disfluencies were relatively more likely to occur in sentence-initial positions than the disfluencies of nonstuttering children. In the same vein, Wall, Starkweather, and Cairns (1981) examined the spontaneous speech of 4-6-year-old stuttering children. Stuttering occurred more on the first uttered word of a clause. In fact, the highest rate of stuttering at clause boundaries was on the conjunction and, especially at the onset of a complex sentence. Note that the same pattern is evident in nonstuttering children. E. M. Silverman (1974) found that nonstuttering 4-year-old children's disfluencies in a spontaneous speech sample were clustered in the first two words of sentences (e.g., "and he ...").

In experimental work with stuttering adults, this pattern of sentence-initial stuttering has been found as well. For instance, the same words are more likely to be stuttered when they are at the beginning of a sentence than when they appear at the end of the sentence (e.g., Hamre \& Wingate, 1973; Jayaram, 1984). Moreover, Tornick and Bloodstein (1976) found more stuttering on the same sentence-initial words when they formed part of a longer sentence than when they formed part of a short sentence (e.g., "she learned to swim in the lake" vs. "she learned to swim"). The fact that this pattern is consistent across stuttering adults, stuttering children, and nonstuttering children implies that something unique happens at sentence-initial positions. In this context, it should be noted that in the spontaneous speech of nonstuttering adults, over half of both filled and unfilled pauses occur at clause-initial positions (Beattie, 1980). Thus, stuttering does not seem to be different in this respect than speech hesitations, and a model of stuttering must account for such a parallel pattern.

Wingate $(1976,1988)$ has argued that this pattern reflects a stress-production deficiency. In English, the words that are stressed are usually in early sentence positions, and, consequently, any difficulties in producing stress are necessarily man- ifest as problems at sentence-initial positions. To test this possibility, Bergmann (1986) had German-speaking participants read a sentence that could serve as an answer to one of two different questions (e.g., "who did that?" vs. "who did that?") A given word in the reply sentence was stressed or not stressed, depending on the question being answered (e.g., "Mrs. Green did that" vs. "Mrs. Green did that"). Stutterers did not differ from nonstutterers in accurately indicating the points at which stress should be assigned, but they stuttered the same words more when they were stressed than when they were not stressed. These findings seem to support Wingate's (1988) stress-production deficiency argument. However, this conclusion is hard to reconcile with Bergmann's finding that the amount of stuttering on stressed syllables in poem reading is far less than the amount of stuttering on stressed syllables in question answering, which requires sentence formulation. Also, Bergmann's study does not preclude the possibility that in utterances with stress in sentence-final position, the rate of stuttering at sentence-initial positions concomitantly increases as compared with the rate of stuttering on other types of sentences.

In keeping with this possibility, research with stuttering adolescents (Prins, Hubbard, \& Krause, 1991) has indicated that stress and sentence position have independent effects on stuttering. More stuttering occurred on the first three words of a sentence, independent of stress, but stressed words were stuttered more than unstressed ones in later positions in the sentence. Moreover, for some participants, the amount of stuttering did not increase on stressed words relative to unstressed ones. Although stress assignment does seem to be implicated in some fashion, the data suggest that it does not account for the sentence-initial stuttering pattern.

\section{Stuttering Is Related to Syntactic Complexity}

There are many studies, with both child and adult stutterers, showing that the more syntactically complex the sentence to be uttered, the more likely stuttering is to occur (e.g., Blood \& Hood, 1978; Brutten \& Hedge, 1984; Gordon \& Luper, 1989; Peters, Hulstijn, \& Starkweather, 1989; Wells, 1979). For example, Gaines, Runyan, and Meyers (1991) found that stuttered sentences were longer and more complex than nonstuttered sentences in 4-6-year-olds' spontaneous conversations with their mothers. If a child attempted a long and complex utterance, the utterance often began with an episode of stuttering.

In an experimental study, Ratner and Sih (1987) compared stuttering 4-6-year-old children in therapy with nonstuttering children matched for age and sex. The children imitated sentences of varying length and complexity. Although sentence length was correlated with the accuracy of sentence imitation in stutterers, it was not significantly correlated with the number of disfluencies. Syntactic complexity, though, was correlated with the number of disfluencies, and syntactically complex sentences were more likely to contain a stuttering moment. Similarly, Wells (1979) found that adult stutterers evidenced almost three times as many disfluencies when producing sentences with three relative clauses than with one relative clause.

Syntactic complexity is also associated with disfluencies in nonstuttering children. Pearl and Bernthal (1980) had 3-5year-old nonstuttering children repeat sentences of differing 
grammatical complexity. More disfluencies were found on passive sentences, which generally appear later in development and are considered more difficult (Menyuk, 1969).

Syntactic complexity is similarly implicated in research that employs oral reading rather than spontaneous speech. As in spontaneous speech, the more complex the reading material, the more stuttering occurs during reading. Blood and Hood (1978) had stuttering children from Grades 3-6 read paragraphs written above and below their own grade placement. For participants in all grades, disfluencies increased with greater difficulty of the reading material. Although ordinarily speech leads to more disfluencies than reading, Blood and Hood found that reading at levels increasingly above one's grade level can yield a greater number of disfluencies than spontaneous speech.

In a different paradigm, Palen and Peterson (1982) used a within-subject design with three groups of stutterers aged 8-12 years who read sentences that varied in complexity and wordfrequency level. The findings indicated more stuttering on more difficult grammatical constructions (e.g., passive and negative sentences).

Again, syntactic complexity appears to have the same impact on the disfluencies of nonstuttering children and adults during oral reading. Hedge (1982), who examined beginning readers ages 5 to 6 , found more disfluencies in reading a difficult oral passage. Similarly, Cecconi, Hood, and Tucker (1977) examined the disfluency rate in nonstuttering children reading above and below their own grade level. These researchers found more disfluencies with greater difficulty of reading passages; the types of disfluencies that increased were those that are considered stuttered rather than normal disfluencies (e.g., part-word repetitions, dysrhythmic phonation, and tense pauses). In research with nonstuttering adults, MacKay (1966) found that participants evidenced more disfluencies when completing ambiguous sentences than when completing unambiguous sentences of similar lexical difficulty.

The effect of syntactic complexity appears to be accounted for in part by difficulties in verb production (St. Louis, Hintzman, \& Hull, 1985). For instance, Colburn and Mysak ( 1982a, 1982b) examined Bloom's (1973) developmental data on four normally developing children to examine disfluency development. They found that the frequency of verb phrases in the disfluent corpus was significantly greater than in the fluent corpus. In stutterers the difficulty seems more severe. Bernstein (1981) found that stuttering children tend to be relatively more disfluent on the verb phrase, especially at the point of initiation of the verb phrase, than at other sentence positions. Similarly, Westby (1974) found that stuttering and nonstuttering 5-year-olds did not differ from each other on developmental sentence analysis scores, but stutterers made more grammatical errors, with verb errors being the most frequent.

The kinds of coping strategies evidenced by the bilingual stuttering child in Karniol's ( 1992) study also indicate that stuttering, long tense pauses, and word repetition tend to occur when verb forms are missing. Whereas the bilingual child in Karniol's study exited from such moments of stuttering primarily by switching to the other language in midsentence or by borrowing missing verb forms from the other language, monolingual stutterers obviously do not have this strategy available. As these data indicate, then, producing appropriate verb forms and syn- tactically complex sentences induces stuttering in stutterers and disfluencies in nonstuttering individuals.

\section{Stuttering Is Related to Deficient Language Skills}

Stuttering children and adults appear to have less well-developed language skills. In most cases, this is manifest only in relatively less sophisticated expressive skills. For instance, Byrd and Cooper (1989) found that stuttering 5-9-year-olds did not differ from their chronological age norms in understanding spoken language but were significantly lower in expressive language skills. Murray and Reed (1977) compared nonstuttering and stuttering 5-year-old children matched for age and Goodenough Draw-a-Man Test scores on both expressive and receptive language skills. They found significant differences between stuttering and nonstuttering children in expressive ability and the ability to use grammatical features of language, but not in auditory comprehension or on the Peabody Picture Vocabulary Test (PPVT).

One could argue, though, that differences between stutterers and nonstutterers in expressive language skills reflect stutterers' attempts to simplify verbal responses as a means of coping with stuttering. A study by Pratt (1984) suggested that the deficiency is more deeply rooted. Pratt compared stuttering and matched nonstuttering preschoolers, 3-6 years old, on a task requiring orally presented sentences to be silently acted out on toy objects. Stuttering children performed significantly worse than nonstuttering children even though no oral production was required. The differences between stuttering and nonstuttering children were especially marked on both active and passive versions of sentences specifying improbable relations (e.g., the dog pats the mother). This finding clearly implicates language comprehension skills rather than expressive skills.

Similarly, in a recent study by Ryan (1992), 3-6-year-old preschool children's fluency scores were found to be significantly correlated with grammatical understanding, which required selection of a picture corresponding to a verbally presented test sentence. Fluency was not correlated with any other language measures. These studies indicated that stuttering children have deficiencies in language skills other than expressive language skills.

Evidence from research with adults warrants the same conclusion. For instance, even on lexical reaction time tasks that require no sentence formulation processes, differences between stutterers and nonstutterers emerge. Both Cross and Olson (1987) and Rastatter and Dell (1987) found that stutterers were slower than nonstutterers in deciding if a visual stimulus is a word, irrespective of whether the response mode was vocal (phonating / $\mathrm{a} /$ ) or manual (pressing a key).

Similarly, Van Lieshout, Hulstijn, and Peters (1991) compared adult stutterers' and nonstutterers' fluent productions on a picture-naming task in which one of four pictures had to be named and a word-naming task in which one equivalent word had to be read. Nonstutterers and stutterers did not differ in their voice reaction time to word naming, but stutterers had greater reaction times on the picture naming task. Although definitive conclusions cannot be drawn because the words were not the same across tasks, the study suggested that stutterers require more time in the lexical search phase and not in the 
articulatory planning phase. Similar conclusions appear to be warranted by recent findings (Viswanath \& Rosenfield, 1991) showing that stutterers' voice onset times are significantly longer when the same word is in sentence-initial position than in sentence-final position; nonstutterers' voice onset times do not evidence such a difference.

A study by Wingate (1984) also sheds light on this issue. Wingate examined the distribution of pauses in the spontaneous speech of stuttering and matched nonstuttering adolescents and adults telling a story about TAT cards. In nonstuttered speech, filled pauses (i.e., ". . . um . . . eh") are more likely to occur following a word than after a silent pause and to be followed by a word than by a silent pause. In stuttered speech, filled pauses were more likely to occur after silent pauses, and words were less likely to be sequelae to filled pauses after silent ones. Although this study is not definitive owing to its correlational nature, pauses are known to reflect delays related to word choice (Butterworth, 1980; Good \& Butterworth, 1980). Thus, this study also suggested that stutterers encounter problems of lexical selection.

A language deficiency is similarly implicated in the finding that in bilinguals, stuttering often occurs significantly more in one language than in the other (e.g., Nwokah, 1988; Ratner \& Benitez, 1985), or is totally absent in the dominant language and varies in severity in the nondominant language (e.g., Dale, 1977; Mattes \& Omark, 1984). The additional finding that DAF induces more stuttering in the nondominant language (e.g., MacKay \& Bowman, 1969) again underlines this pattern.

\section{Many Successful Therapy Programs Teach Language Skills}

It is generally acknowledged that learning language skills reduces stuttering (e.g., Eisenson, 1986; Mattes \& Omark, 1984). Even though many stuttering therapy programs for adults include language skill training, this aspect of the programs is usually ignored in theoretical discussions of their therapeutic effectiveness. For instance, Azrin and Nunn (1974) used a treatment program whose salient features included taking a deep breath to relax the throat and chest muscles; but the program also required the individual being treated to mentally formulate the content of the conversation.

In contrast, almost all therapy programs for young stutterers explicitly incorporate some training in language skills. For instance, Riley and Riley (1979) included training in sentence formulation in their treatment program for young stutterers. Ryan's (1974) treatment program focused on the linguistic complexity of utterances, starting with utterances that were 30 $\mathrm{s}$ in length and increasing to $5 \mathrm{~min}$ in length. Shine's (1980) therapy program started with a 50-word collection that the child could produce fluently and built longer and more complex utterances on these words. Although the absolute level of success of such therapy programs is a contentious issue (e.g., Andrews, Guitar, \& Howie, 1980), any degree of success of programs whose focus is on language skills is hard to reconcile with models of stuttering in which chronic malfunctions of the articulatory system are posited.

\section{Spontaneous Recovery From Stuttering Is the Rule Rather Than the Exception}

The majority of children who stutter recover spontaneously without therapeutic intervention of any sort. Andrews and Harris (1964) reported a 79\% spontaneous recovery rate. Sheehan and Martyn (1970) found an $80 \%$ spontaneous recovery rate reported by individuals who indicated they had a stuttering problem in the past. In one study that examined this issue directly, Panelli, McFarlane, and Shipley (1978) reinterviewed $7-$ year-old children who had been diagnosed as stutterers between the ages of 2 and 5 years, with 3 being the average age of stuttering onset. None of the children had been treated and all had scored within 6 months of their chronological age on the PPVT. About $80 \%$ were found to have recovered and showed no evidence of a stutter. In a recent longitudinal study initiated at a mean age of 36 months (within 1 year of stuttering onset), Yairi and Ambrose (1992) found that 18 of 27 children had fully recovered within 2 years, and only 3 of the remaining children continued stuttering through the elementary school years. In another longitudinal study with 25- to 39-month-old stutterers, Yairi, Ambrose, and Niermann (1993) found a significant decrease in stutterlike disfluencies over a 6 -month period with no therapeutic intervention.

Although conclusions about the absolute rate of spontaneous recovery cannot be drawn because many children are not referred to speech pathologists, the fact that there is spontaneous recovery poses a challenge for models of stuttering. It is possible to account for spontaneous recovery by arguing that developmental stuttering and chronic stuttering do not represent the same underlying process. This would imply that one needs two different models of stuttering: one that accounts for developmental stuttering and one that accounts for chronic stuttering. Alternatively, one must posit a model of stuttering that can account for both developmental and chronic stuttering but does not assume a chronic malfunction in individuals who show spontaneous recovery. As I discuss later, the majority of theorists have focused on the chronic syndrome and have ignored developmental stuttering.

\section{Stutterers Evidence No Chronic Dysfunction but Do Evidence Greater Variability in Speech Motor Coordination}

Fluent speech requires coordination and synchrony of respiratory, phonatory, and articulatory movements. Theorists have often suggested that stutterers either have a chronic dysfunction in part of the speech system or, for some reason, have difficulty coordinating and synchronizing the required laryngeal and articulatory systems (e.g., Van Riper, 1971; Wingate, 1976).

In one line of research that has addressed this issue, investigators have examined the articulatory variation between specific phonemes and have focused on the number of voiced and voiceless transitions in a given speech segment. If stutterers have difficulty coordinating the articulators, making transitions from voiced to voiceless phonemes (e.g., /b/, /g/, /d/ vs. $/ \mathrm{p} /, / \mathrm{k} /$, $/ t /$ ) should be difficult for them. Several researchers have failed to obtain support for this hypothesis. For instance, Runyan and Bonifant (1981) had stuttering children 7-13 years of 
age read two equivalent reading passages, one with all voiced sounds and the other with both voiced and unvoiced sounds. Stuttering rates did not differ significantly for the two passages. Similarly, McGee, Hutchinson, and Deputy (1981) found no significant differences in disfluencies during reading of voiced versus voiceless passages by children who stutter.

Researchers have also examined temporal measures of speech coordination such as voice onset time (VOT), defined as the temporal interval from stop release burst to when the vocal chords start vibrating. Their findings are mixed. For instance, the majority of studies requiring individuals to produce a vowel sound in response to auditory tones found no differences in reaction time between stuttering and nonstuttering adults (Venkatagiri, 1981) or children (e.g., Cross \& Luper, 1979; Cullinan \& Springer, 1980; Murphy \& Baumgartner, 1981 ). In other studies, voice reaction times of stutterers were found to be longer and more variable than those of nonstutterers (e.g., Cross, Shadden, \& Luper, 1979).

In contrast to these studies, which required only vowel sounds to be produced, Adams (1987) examined VOT in 4year-old stuttering and matched nonstuttering children responding to standardized questions about a series of drawings. The tapes were edited to compare the same words when fluent and in the same sentence position in both stutterers and nonstutterers. VOT was found to be longer in the stuttering children. Initial consonant durations and vowel durations were also longer in the stuttering children. Moreover, the variability of the stuttering children on all these measures was greater than that of the nonstuttering children. Hence, there is some indication of greater variability on temporal measures of stutterers' speech.

In another line of research, investigators have used physiological indexes that assess coordination of the articulators (e.g., laryngeal movements and jaw muscles). Because of the methodological difficulty of assessing coordination of the articulators in young children, relatively few studies have included such measures. In several well-controlled studies conducted by Conture and his colleagues, there was no evidence of any significant differences in the sequence of temporal onsets of respiratory, phonatory, and articulatory behaviors between young stutterers' stuttered speech versus their age mates' fluent speech (Caruso, Conture, \& Colton, 1988) or between the fluent utterances of stutterers versus nonstutterers (Conture, Colton, \& Gleason, 1988). Molt (1991) compared both the fluent and nonfluent utterances of stuttering and nonstuttering children age 5-6 years. The children were required to attend to a signal tone and repeat a modeled phrase containing a target monosyllabic word with $/ \mathrm{p} /$ in initial position. The measures included VOT, vowel duration, vocal fold activity as measured by electroglottograph electrodes, and velar movement onset as recorded by a nasal microphone. Although no between-groups differences were found on any of the measures, greater variability in velar movement onset for stuttered utterances was evident in the data.

With adults, a similar pattern emerges. Prosek, Montgomery, Walden, and Schwartz (1979) measured reaction times (RTs) of stutterers and nonstutterers to a flash of light, a tone, or a word and required either a button press or a word to be read as a response. They found no between-groups differences on manual $\mathrm{RT}$, verbal RT, or electromyographic (EMG) activity. Weiner
(1984) used EMG to measure vocal fold movement and found no differences between the fluent utterance of words of both stutterers and nonstutterers. Janssen, Wieneke, and Vaane (1983) measured the onset of EMG activity of the articulators during fluent productions of words in male adult stutterers versus mixed-sex nonstutterers. Again, although no betweengroups differences emerged, stutterers evidenced greater variability in speed of onset of movements of the articulators.

These lines of research converge in showing that stutterers do not appear to have a chronic dysfunction of the articulatory system. Stutterers do appear to evidence greater variability than nonstutterers on both temporal and physiological measures assessing the coordination of the articulators and the initiation of speech. It is this greater variability, then, that must be accounted for in models of stuttering.

\section{Summary of Research Findings}

To summarize, stuttering appears to be a problem some young children, some adults, and some bilingual individuals have with speaking in sentences with sentence-initial words, with syntactically complex sentences, and with difficult verb forms in particular, eventuating in greater stuttering. For the majority of young children, the problem tends to disappear with development. However, the data suggest that in those individuals in which stuttering persists, there is a concomitant language difficulty that is evident in their need for more time to initiate sentence production and in low expressive and occasionally receptive language scores as well. A model of stuttering must not only account for this pattern of findings but must also address the similarity between stuttering and other nonstuttering disfluencies in terms of when and where they occur. Next, I examine how well different models of stuttering account for the pattern of findings.

\section{Current Models of Stuttering and Their Limitations}

\section{Timing Disorder Models}

In many models, stuttering is discussed as a dysfunction that involves a timing disorder of the speech muscle control system (e.g., Kent, 1983a, 1983b; MacKay, 1987; MacKay \& MacDonald, 1984). For instance, MacKay's (1987) theory, which is unique in its attempt to account for stuttering in bilinguals and the effects of DAF, involves a hierarchically arranged series of nodes, each of which has a different priming and recovery cycle. Nodes need to be activated in a sequence that matches the utterance to be produced, where each node corresponds to some part of the utterance. As the individual utters one part of the sentence, the node relevant for that part of the utterance selfinhibits, and the next node is activated. Self-inhibition of nodes after they are activated prevents these nodes from interfering with production of subsequent parts of the utterance. For instance, muscle movement nodes are ordinarily self-inhibited after activation, and self-inhibition prevents normal auditory feedback from causing stuttering (MacKay \& MacDonald, 1984). Breakdowns in the timing mechanism that controls muscle movement nodes interfere with self-inhibition and lead to stuttering. Specifically, the muscle movement nodes of stut- 
terers are assumed to exhibit an abnormal priming and recovery cycle such that priming builds up abnormally slowly and rebounds abnormally sharply following self-inhibition. When self-inhibition is delayed, the continuation of behavior occurs and sound prolongation results. When self-inhibition occurs too early, the node may be reactivated, and sound repetitions result. Within MacKay's model, then, stuttering is an outcome of periodic disruptions in the timing of muscle movements within the speech system.

Although MacKay's ( 1987) model accounts for a wide range of findings in the stuttering literature, it has some important limitations. First, the model does not account for age of stuttering onset, sentence-initial stuttering, or the higher incidence of stuttering on syntactically complex sentences. Second, the model cannot account for the relation between stuttering and receptive language deficits. Finally, the model does not fully account for spontaneous recovery from stuttering because there is no a priori reason to assume that any malfunction of the timing mechanism should manifest itself differently across languages or that it may be self-corrective. ${ }^{4}$

An elegant theory presented by Rosenfield and Nudelman (Nudelman, Herbrich, Hoyt, \& Rosenfield, 1989; Rosenfield \& Nudelman, 1987) also posits timing as the critical variable. They and their associates view disfluencies as momentary instabilities in a multiloop system in which temporal synchrony has been disrupted. Specifically, speech motor control consists of two major control loops: an outer loop containing all the ideation and linguistic programming needed for speech production, and an inner phonatory loop containing both motor programming and control of the vocal apparatus. In this system, disfluency can occur if the inner phonatory loop is stable but the outer loop adds enough phase lag caused by increased processing time to make the system unstable. Instability is momentary, making the intended speech motor output impossible. Stuttering thus occurs in response to momentary instability of the speech motor control system. In this model, disfluencies can occur even when all the components are functioning properly.

Despite the obvious advantage of the model in accounting for both fluency and disfluency, it has several important limitations. First, the data supporting the model are based on tracking of sound waves by humming. It is difficult to see how such a task relates to spontaneous speech production. Second, the model leaves aspects of stuttering unexplained. For example, how can one account for the locus of stuttering events or for the apparent similarity between normal disfluencies and stuttering in terms of their involvement in speech phenomena?

\section{Feedback Models}

Many theorists have assumed that stuttering results from problems in the way stutterers hear their own voices (e.g., MacNeilage, 1980, 1981; Sorokin, 1975). The auditory system is assumed to have some malfunction that causes stutterers to experience DAF. If speech requires the precise synchrony of information from the auditory system and from the speech production system at some point of intersection, then DAF may disrupt this synchrony. The individual may think he or she has not uttered a given syllable and repeat it. Stuttering is the result of self-correction that stems from a chronic delay in hearing one's speech output. The finding that stuttering can be induced in nonstuttering individuals by exposing them to DAF of 200 ms (MacKay, 1987) is consistent with this line of reasoning.

Also consistent with feedback theories is the finding that in stuttering individuals exposed to noise that makes it impossible for them to hear their own voices, stuttering is significantly reduced (Brayton \& Conture, 1978). However, the finding that it makes no difference to stutterers if noise occurs during vocalization, during silent pauses, or continuously (Sutton \& Chase, 1961) creates serious difficulties for feedback theories (Bloodstein, 1993; Garber \& Siegel, 1982; Zimmermann, Brown, Kelso, Hurtig, \& Forrest, 1988).

From the point of view of feedback models, if one could reduce the delay with which stutterers get auditory feedback, they should not need to repeat the presumably unuttered item; consequently, stuttering would be reduced. Because there is no obvious way of reducing the delay with which one hears one's own voice, investigators have used longer delays and exposed stutterers to delayed and amplified auditory feedback (MacKay, 1987). In such research, stuttering has been shown to be maximally reduced by providing stutterers with DAF of $400 \mathrm{~ms}$. If in fact stutterers' condition is that they hear their own voices with a delay of approximately $200 \mathrm{~ms}$, then it is not intuitively obvious why increasing the delay even more should be fluency enhancing.

There are several additional problems with feedback theories in accounting for stuttering. First, there is no physical evidence for any auditory malfunction that is associated with stuttering. Second, most stuttering moments occur at sentence-initial positions rather than at midsentence positions. Auditory feedback cannot be a relevant factor in guiding speech or interfering with speech at sentence-initial positions, precisely where stuttering is the most prevalent.

Moreover, given that preparatory articulatory activity is demonstrable between 100 and $200 \mathrm{~ms}$ before the associated speech sounds are produced (Fujimura, 1979), it is difficult to see how auditory feedback, which can take between 150 and $250 \mathrm{~ms}$ before it is received, can be used in speech production. This is not to say that auditory feedback cannot be used to make spontaneous corrections (cf. Laver, 1973) but rather that in fluent speech, auditory feedback is not used to guide one's speech in an anticipatory fashion. Finally, to the extent that a chronic malfunction is assumed, feedback models cannot account for periods of fluency in stutterers, language-specific stuttering in bilinguals, age of stuttering onset, or the involvement of lexical and syntactic factors in the stuttering moment.

\section{Interactional Models of Stuttering}

Recently, several theorists have posited interactional models of stuttering in which some predisposition of the child interacts with social or environmental factors to produce stuttering. The

\footnotetext{
${ }^{4}$ As was noted by one of the reviewers, developmental problems may in fact be self-corrective. However, even if one assumes that developmental stutters suffer from a self-corrective problem, one must account for the way stuttering is manifest in both children and adults and explain why in some individuals the problem is self-corrective while in others it becomes chronic.
} 
most widely accepted model, the demands and capacities model (Adams, 1990; Andrews et al., 1983; Starkweather, 1987; Starkweather \& Gottwald, 1990), accounts for periods of fluency as well as disfluency. When children's capacity for fluency exceeds the demands placed on them, they talk fluently. Stuttering occurs when children lack the capacity to meet fluency demands. Environmental demands (e.g., parents who speak quickly themselves, or tell the child to speak more quickly or to finish his or her sentences) produce disfluencies through the effects that such demands have on increased air pressure and stiff speech musculature. Although this model appears able to account for many aspects of stuttering, including age of onset and the involvement of syntactic variables and bilingualism, the problem with such a model is its circularity. When children evidence disfluencies, environmental demands exceed their capacity; when children are fluent, environmental demands do not exceed their capacity. Any model that suffers from circularity is unlikely to prove scientifically useful in the long run.

W. H. Perkins, Kent, and Curlee (1991) have recently presented a more intricate theory. They argued that "two primary conditions are required for stuttering: disruption of speech flow with varying levels of awareness of cause, and pressure to continue speaking during such disruption" (p. 747). They assumed that for whatever reason all speakers occasionally experience disruptions in the flow of speech. However, speakers differ on the awareness dimension. When there is awareness of the causes of disruption of the speech flow, normal disfluency results; however, when there is no awareness of the causes of these disruptions, stuttering occurs. Both disfluencies and stuttering result from dyssynchrony either within or between the various systems involved in speech production, but "time pressure is required for the resulting disfluency to be stuttered" (W. H. Perkins et al., 1991, p. 739). The amount of stuttering is assumed to vary as a function of the loss of control in that loss of control varies with the intensity of dominant-subordinate conflict, and this conflict is predominant among males. Perkins et al. presented no data testing the theory directly but promised to do so in future articles.

The more problematic point from my perspective is that Perkins et al. (1991) made several assumptions that appear to be unwarranted. First, they did not account for why awareness of the cause of disfluency is such a critical factor in the model. Second, given that stuttering onset is roughly between the ages of 2 and 3 years, could the awareness dimension differentiate stuttering from nonstuttering children at this age? Third, why would dominance-subordinance conflict be more severe for those who stutter? Fourth, the authors suggested that stutterers' perseverance in getting out the stuttered word is an indication of social pressure to continue speaking combined with time pressure to complete the utterance within a limited time frame. They confounded the two types of pressure, providing no adequate reason for accepting this assumed equivalence. Finally, the model does not account for the intricate relationship between sentence position, syntactic complexity, and stuttering.

\section{Summary of Models}

Each of the models accounts for some aspects of stuttering but not others. For the most part, theorists have ignored the developmental implications of the age of stuttering onset and spontaneous recovery; both of these findings seem to demand a model that is grounded in development rather than in a chronic dysfunction. Next, I present a new model that can account for the available research evidence.

\section{Stuttering as Suprasegmental Sentence Plan Alignment} (SPA)

In my model, stuttering symptoms (whole-word repetition, part-word repetition, blocking, and word elongation) occur in both stuttering and nonstuttering individuals because of the following: (a) Words are produced differently in sentence contexts than in isolation; (b) the way a word is produced depends on the sentence in which it is embedded; (c) sentences have suprasegmental features, including rhythm, melody, and stress, that are largely determined prior to utterance initiation and are expressed through changes in muscle movements; (d) individuals change their speech plans online, during sentence production; (e) latency of producing online changes reflects time required for lexical search, syntactic revisions, and suprasegmental sentence plan revision; and (f) word elongations and part-word and whole-word repetitions represent points of alignment of planned suprasegmental features with the revised suprasegmental features of sentences.

In essence, the model posits that disfluencies of all types are a result of the fact that speech is an intricate process that combines both preplanned elements and active, online revisions. Next, I elaborate each of the above tenets and cite research evidence to support them. Finally, I show how the model accounts for developmental stuttering, chronic stuttering, and other important stuttering phenomena.

\section{Words Are Produced Differently in Sentence Contexts Than in Isolation}

A model of stuttering must account for why stuttering is more likely on the same words in sentence contexts than in isolation. There is abundant evidence that words are produced differently in sentence contexts than in isolation. First, there is developmental evidence at the point of transition from the one-word stage to multiword utterances that words are produced differently as part of an utterance than in isolation. These differences involve both temporal changes and changes in voice fundamental frequency (i.e., the frequency of vibration of the vocal chords). The duration of nonfinal words in young children's multiword utterances is compressed as compared with the duration of the same words in isolation (Branigan, 1979; Kubaska \& Keating, 1981). Differences in word duration are achieved by changes in the way vowels and syllables are expressed. When children start using multiword utterances, they change the way they utter their syllables and vowels, from the full form typically used in the earliest polysyllabic words to the shortened forms used in mature, fluent phrases (Allen \& Hawkins, 1980). By the age of 5, children evidence adultlike vowel durations when a word is part of a phrase as opposed to when it is said in isolation (Beardsley \& Cullinan, 1987).

Second, Menyuk and Klatt (1975) found that in both children and adults the voice fundamental frequency of a given 
word uttered in isolation is different than that of the same word uttered in a sentence context. In line with this, Branigan (1979) found that as children begin to produce two-word utterances, the second word of the utterance contains a greater fundamental frequency at the end of the word than does the first word of the utterance, a pattern analogous to that found in adult speech.

Third, extensive research on coarticulation patterns in adults (Kent \& Minifie, 1977; Whalen, 1990) has indicated that the way a word is produced depends to a large extent on the words that are adjacent to it. In fact, when word lists are reversed to form sentences, they are read faster and much more accurately (Lackner \& Levine, 1975), most likely because of coarticulation effects. That is, when people speak in sentences, the configuration of the vocal tract necessary for the next word is simultaneously implemented by commands sent to the appropriate muscles, before the final syllable of the word being uttered. The anticipatory effects of coarticulation can be detected in muscle movements up to $600 \mathrm{~ms}$ before such coarticulation actually occurs (Kent \& Minifie, 1977; Lubker, 1981).

Thus, in terms of voice fundamental frequency, timing, and coarticulation, words are produced differently in a sentence context than when they are produced in isolation. Words do not have unique articulatory representations, but rather can be uttered in a variety of articulatory patterns. Most important, the features of words that change when they are embedded in sentences are suprasegmental features.

\section{The Way a Word Is Produced Depends on the Sentence in Which It Is Embedded}

Given that words do not have unique articulatory representations, what determines how a given word is articulated in a given sentence context? How a word is produced depends on its position in the sentence and whether it is stressed or not. Both the position of a word in the sentence and word stress influence its rhythmic and melodic manifestations. Changes in word stress are achieved by changes in voice fundamental frequency, amplitude, and word duration (Farnetani \& Kori, 1986), either in combination or alone. The durational correlates of stress vary with word position. When stress occurs early in the utterance, later segments are shortened; when stress occurs late in the utterance, there are no durational changes evident in producing words early in the utterance (Weismer \& Ingrisano, 1979).

Similarly, the changes in voice fundamental frequency that occur due to word stress are context dependent. When the stress pattern of the word is varied at sentence-initial position (e.g., the Japanese words Isinicikai vs. isInicikai, with capitals indicating stress location), the word is implemented with a different fundamental frequency contour (Fujimura, 1979); concomitantly, there is different activity of one of the laryngeal muscles (the cricothyroid muscle), with a lead of about $100 \mathrm{~ms}$ in muscle activity that predicts the different fundamental frequency contours. The involvement of such muscles in modulating voice fundamental frequency implies that variability in fundamental frequency during speech should be accompanied by variability in muscle movements. In fact, the laryngeal muscles actively participate in regulating voice fundamental frequency (Hirano, Ohala, \& Vennard, 1969). Greater activity of two la- ryngeal muscles increases voice fundamental frequency (Shipp, McGlone, \& Morrissey, 1972). Consequently, when a word is uttered in a phrase context versus in isolation its fundamental frequency is different, and it is articulated in a different constellation of muscle movements (Fujimura, 1986; Hirano et al., 1969; Kent \& Netsell, 1971).

Beyond the level of the word, there is evidence that the syntax and pragmatics of the utterance determine both rhythmic and melodic sentence characteristics. There are two basic suprasegmental features of sentences: rhythm and melody. Rhythm refers to the duration of segments and their interrelation with larger units. Rhythm includes features like voice onset time, the duration of pauses between words, the duration of each segment, and the total duration of the utterance. Melody is equivalent to the tonal structure as expressed in the fundamental frequency contour. Every utterance necessarily has rhythm because of the sequential nature of speech, and every utterance has melody (unless it is whispered) because the frequency of vocal chord vibration changes during speech. The effect of sentence syntax and pragmatics has been shown on various suprasegmental features including sentence rhythm, intonational contour as measured by voice fundamental frequency, and sentence accent (Allen \& Hawkins, 1980; Brazil, 1984; Cooper, 1980; Cutler, 1984; Fuchs, 1984; Garro \& Parker, 1982, 1983; Lehiste, 1970).

The changes induced by syntax apparently include systematic temporal variations such as the duration of pauses between words (Fujimura, 1981) and, concomitantly, changes in the coarticulation pattern. Syntax and pragmatic considerations also appear to be involved in determining the stress pattern of utterances and of specific words in the utterance. The stress pattern of the phonological representation of words in the mental lexicon is apparently represented independently (Halle, 1985), and the syntax of the sentence will often determine the stress pattern attached to a given word (Cutler, 1984). Changes in the stress pattern of a sentence are associated with a different constellation of articulatory movements (Fujimura, 1986; Hirano et al., 1969; Tuller, Harris, \& Kelso, 1982). More important, suprasegmental features can be specified only after each word is assigned to a given position in the sentence.

\section{Sentences Have Suprasegmental Features That Are Largely Determined Prior to Utterance Initiation and Expressed Through Changes in Muscle Movements}

Given that words uttered in sentence contexts differ in their suprasegmental characteristics depending on the sentence in which they are embedded, I must address the issue of how suprasegmental characteristics are related to sentence production and how suprasegmental characteristics are realized.

The most important aspect of suprasegmentals is that both the temporal structure and the intonational contour of sentences are largely determined prior to utterance initiation. Speakers appear to have some knowledge of the length of the utterance they plan to produce before they begin the utterance; a "look ahead mechanism" (Cooper \& Sorenson, 1981) concerned with the planned length of utterances feeds into the planning of suprasegmental features prior to the initiation of production of the utterance. Although it might seem difficult to 
draw conclusions about the point at which suprasegmental features are determined, any feature that differs at sentence-initial position as a function of some aspect of the utterance that appears later would certainly seem to indicate that anticipatory processes guided the realization of the specific feature in question. In fact, there is abundant evidence for such anticipatory processes in the assignment of both temporal and melodic suprasegmental features.

The volume of air inspired before the onset of phonation is proportional to the length of the planned utterance (Lieberman, 1967). In fact, Flege (1983) found that supraglottal air pressure in utterance-initial words is related to the length of the subsequent utterance. In the temporal domain, word duration has been shown to be a function of the total duration of the utterance (Lehiste, 1980). Vowel durations also change as a function of the number of words that follow them (Lyberg, 1977), a phenomenon labeled anticipatory lengthening ( Van Lancker, Kreiman, \& Bolinger, 1988). Such sensitivity to sentence length has been found in young children as well. Research has indicated that children 3-5 years old change their vowel durations as a function of word position in the sentence (Konefal, Fokes, \& Bond, 1982).

Lehiste and Ivic (1986) found that the anticipatory effect extends to the melodic representation of words. The position of a word within a sentence affects the manifestation of its fundamental frequency patterns as well as its duration. Similarly, Cooper and Sorenson (1981) found that the value of peak fundamental frequency of matched key words in long versus short sentences was significantly higher at sentence-initial positions in long sentences. Finally, intonational decisions are made prior to utterance initiation (Sternberg, Monsell, Knoll, \& Wright, 1980 ); either a rising or a falling intonation pattern is adopted for different types of sentences.

In this context, it should be noted that the effects of planned utterance length are apparently independent of the need to inhale. Taking a new breath does not necessarily cause changes in fundamental frequency (Hart, Collier, \& Cohen, 1990). Many resettings of fundamental frequency occur when inhalation does not, and vice versa (Cooper \& Sorenson, 1981). Moreover, airflow is unrelated to changes in voice fundamental frequency (Shipp et al., 1972).

\section{Individuals Change Their Speech Plans Online, During Sentence Production}

Speakers often change their speech plans online (Deese, 1980); both lexical and syntactic decisions are made online during speech (e.g., Bock, 1986; Ford, 1982; Ford \& Holmes, 1978). Such online changes occur because speech is often initiated before all planning has been completed (Kempen \& Hoenkamp, 1987), especially planning of the verb phrase (Lindsley, $1975,1976)$. When for some reason there is a problem in completing the utterance as planned, online changes are implemented.

There are three kinds of online changes in speech plans (cf. De Smedt \& Kempen, 1987). In frame shifts, the initially planned utterance is changed, and a different syntactic frame is used than originally planned (e.g., "He . . . They got him a watch"). No account is taken of the initially attempted part of the utterance; the utterance is completed as if the original frame had not been initiated. Experimental evidence for frame shifts comes from research on lexical inaccessibility. Bock (1987a, 1987b) and Levelt and Maassen (1981) found that lexical inaccessibility often results in changes in the way the meaning of the utterance is conveyed, including changing from active to passive voice. In frame elaborations, some part of the utterance is retained, retracing occurs, and additional elements are inserted (e.g., "The girl was . . . the girl holding the flowers was very pretty"). Frame elaborations have been well documented in research on self-repairs and speech errors (Blackmer \& Mitton, 1991; Fromkin, 1971; Garrett, 1980; Levelt, 1983). Frame discards occur before utterance initiation even begins. How then does one know that such discards actually occur? First, there is anecdotal evidence (e.g., Hockett, 1973; Shattuck-Hufnagel, 1979) for "errors in the head" that are not articulated. Second, there is also experimental evidence for frame discards from an innovative series of studies on spoonerisms (e.g., Motley \& Baars, 1979). When spoonerisms would result in utterances that are taboo for some reason, including sexual connotations, the way they are uttered is changed prior to utterance initiation to avoid such connotations. Given the fact that all three types of frame changes take place online, suprasegmental features of the sentence that were determined prior to utterance initiation may no longer be appropriate and may need to be changed as well.

\section{Latency of Producing Online Changes Reflects Time Required for Lexical Search, Syntactic Revisions, and Suprasegmental Sentence Plan Revision}

Some of the time needed for frame changes is spent searching for alternative ways of conveying the intended meaning of the utterance (Blackmer \& Mitton, 1991; Laver, 1980). In an analysis of spontaneous corrections of speech during a call-in radio program, Blackmer and Mitton ( 1991) found that conceptually more complex corrections took longer to complete. In experimental work, Bock (1987a, 1987b) found significant sentenceinitial disfluencies, (including filled pauses, long hesitations, and false starts) as a result of phonological priming. Priming made a relevant lexical item temporarily inaccessible at the point of utterance initiation and, concomitantly, led to frame shifts. Levelt and Maassen (1981) similarly found longer latencies to sentence initiation when a difficult rather than an easy lexical item was in sentence-initial position. However, the time needed for finding alternative lexical items is not limited to sentence-initial disfluencies; Levelt (1983) found that changing planned frames results in longer utterance durations as well.

Additionally, some of the time required for implementing frame changes is needed for implementing changes in the suprasegmental features assigned at both the sentence and the word level (Cutler, 1980). For a frame change to be implemented, a new suprasegmental pattern must be imposed on the newly planned or revised utterance. Suprasegmental features are expressed by changes in muscle movements within the articulatory system; consequently, online changes necessitate interruption of such muscle movements (Laver, 1973) and of anticipatory muscle movements in particular. Muscle activity that has been initiated in preparation for upcoming segments and features must be stopped. Although ordinarily the integrity of 
individual words is preserved and interruptions occur at word boundaries (Nooteboom, 1980), interruptions can occur within words. This can result in the temporary blocking of articulatory activity ( $\mathrm{cf}$. Laver, 1980). In addition, because some muscle movements have to be stopped and others have to be initiated to carry out production of the revised utterance, changing suprasegmental features online leads to greater variability in muscle movements.

\section{Word Elongations and Part-Word and Whole-Word Repetitions Represent Points of Alignment of Planned Suprasegmental Features With the Revised Suprasegmental Features of Sentences}

When frame changes are implemented, the suprasegmental features of the planned utterance and the suprasegmental features of the revised utterance need to be aligned. Each word must be uttered in a manner consistent with the newly derived suprasegmental plan. Accordingly, speakers must align the suprasegmental features so that the remaining part of the sentence that has not yet been produced can be adequately produced. The point at which the alignment occurs is essential to the proper production of the revised and remaining suprasegmental speech plan. The suprasegmental speech plan demands that each sentence segment be produced in a way that is consistent with the remaining part of the plan that is yet to be produced. Thus, speakers persist in getting the disfluent word out because without it they cannot implement the revised suprasegmental plan and continue the utterance. This "fluency" need results in two related phenomena: the retracing that occurs in spontaneous self-repairs and the word elongations and part-word and whole-word repetitions that occur in disfluent speech.

In spontaneous self-repairs, it has often been noted that retracing occurs to the point where a syntactically coherent phrase results, even though the retracing may include words that were not erroneously uttered (Nooteboom, 1980). Similarly, Cutler (1980) has noted that stress and intonation errors, whether at the word or the sentence level, lead to retracing prior to the point where the error occurred. Such retracing is consistent with the need to implement the suprasegmental speech plan. Thus, when the suprasegmental pattern of the revised utterance does not extend naturally from the previous pattern, the speaker must align the two suprasegmental patterns prior to continuing the utterance.

The fact that spontaneous repairs are often distinguished from the original utterance by their prosodic shape (Cutler, 1983 ) supports this interpretation. Moreover, the fact that such retracing in spontaneous repairs occurs in children under the age of 3 (Wijnen, 1990), who tend to make few adjustments to account for their listeners (Shatz, 1983), suggests that retracing does not occur for the listener's benefit. Rather, the need to retrace can be explained by assuming that the interrupted word is crucial to the production of the melodic and rhythmic plan of the remaining part of the utterance. In fact, there is evidence (Konefal \& Fokes, 1985) that even in children 2-6 years of age, spontaneous repairs often involve changes in fundamental frequency. It is interesting in this context that Pearl and Bernthal (1980), who had 3-5-year-old nonstuttering children repeat taped sentences, found that $76 \%$ of their disfluencies occurred at the point of, or within one word of, the sentence imitation error. Once an error has occurred, SPA is required, and this can lead to disfluencies, as Pearl and Bernthal found.

The similar involvement of SPA in word elongations and part-word and whole-word repetitions in stuttered speech is supported by various types of data. Research on stuttering moments in children has indicated that various suprasegmental features, such as voice fundamental frequency, are changed from the point of onset of the stutter to the point at which fluency is resumed (Healey \& Bernstein, 1991). Moreover, recent research with adults indicates that the fundamental frequency of disfluent vowels is significantly higher than that of the same vowels when fluent (Howell \& Williams, 1992), and the aborted voicing trials of stutterers repeating four-digit numbers have abnormally high voice fundamental frequencies (Borden, Baer, \& Kenney, 1985). If stuttering occurs at those points where voice fundamental frequency must be aligned, one would expect nonstutterers to evidence similar changes in voice fundamental frequency at points of disfluency. Healey and Bernstein (1991) found that the disfluencies of nonstuttering children exhibited similar changes in voice fundamental frequency from the point of disfluency onset to the point of fluent articulation.

The fact that moments of stuttering often occur with abnormally high voice fundamental frequency (Borden et al., 1985), coupled with the prevalent tendency of stutterers to stutter with successively longer portions of the target word (Sheehan, 1974; e.g., "th-_ thir - thirty-five") suggests that part-word repetitions occur to adjust the fundamental frequency with which voicing was initiated. In their analysis of stuttered speech, Borden and her colleagues (1985) found that stutterers often "break the block" by repeatedly reducing the fundamental frequency of the attempted item. Borden et al. also found that only during the final attempts, when no disfluencies occur, is the fundamental frequency of the item similar to the fundamental frequency of the same item produced by a nonstuttering individual. Other researchers (Falck, Lawler, \& Yonovitz, 1985) found that the mean fundamental frequency of stuttered words was lower and more variable prior to the onset of the stutter than of the same words when fluent. This greater variability in fundamental frequency of stuttered items is consistent with the greater variability of the cricothyroid laryngeal muscles during disfluent productions than during fluent productions of the same words (Freeman, 1975). In fact, repeated disfluencies on the same words over time are not produced by the same speaker in the same way (Venkatagiri, 1980), and stuttering of the same words looks different in terms of the muscle movements accompanying the disfluency each time (Freeman, 1975; Shapiro, 1980). This pattern is consistent with the possibility that disfluent speakers attempt to adjust voice fundamental frequency by repeating the word.

Thus, both retracings in spontaneous self-repairs and the kinds of disfluencies that are symptomatic of stuttered speech appear to entail changes in suprasegmental features, especially voice fundamental frequency. Such changes in suprasegmental features are occasioned by online frame changes. Consequently, disfluencies in both nonstuttering and stuttering individuals can be accounted for within a sentence production framework in which online revisions occasion the need for SPA. Note that although the data are not fully consistent, disfluencies seem to 
occur primarily when voice fundamental frequency is too high rather than too low. Next, I consider how SPA can account for other phenomena associated with the stuttering syndrome.

\section{Using the SPA Model}

\section{Accounting for Developmental Stuttering}

My model suggests that individuals who are linguistically less competent, either developmentally or chronically, will evidence more stuttering. The need for SPA is more likely to occur at the point in development where sentence planning strategies are being acquired and online morpholexical insertion is not yet proficient. Because speech is initiated before all planning has been completed, this could account for the greater difficulty of stuttering children with syntactically complex sentences and with verbs. Because changes in syntax necessarily change many suprasegmental features, children must engage in SPA as they engage in online processing.

Evidence for developmental changes in online processes during sentence production come from many sources. Sabin, Clemmer, O'Connell, and Kowal (1979) found a significant decrease in false starts (e.g., "Realizing he's . . . he suddenly realizes") and repeats (e.g., "The . . . the girl came") on a spontaneous narrative task from kindergarten to ages 10-13. Similarly, Kowal, O'Connell, and Sabin (1975) found developmental changes in the kinds of repetitions that occurred on a cartoon description task. Repetitions of single syllables occurred only in children in kindergarten through fourth grade; repetitions of one word, which represented $47 \%$ of all repetitions, decreased significantly with age, as did false starts.

Stuttering apparently has its onset prior to age 3; the SPA process I have described may not seem a plausible explanation for stuttering in such young children. Yet research on word errors (e.g., Jaeger, 1992; Wijnen, 1988, 1990) has indicated that children do attend to these aspects of their speech and correct phonological, lexical, morphological, and prosodic features of their speech at these ages. Moreover, as Wode (1980) has argued, children start to use these features in their speech prior to the onset of sentence production, during the one-word and twoword stage. Branigan and Stokes (1984) found that even in the one-word stage, children spontaneously reorganize their utterances, prosodically integrating the original, temporally fragmented form, like stutterers' tendency to repeat increasingly larger segments of the word. In fact, Echols (1993) has recently found that children between the ages of 2 and 3 reproduce words by imitating their prosodic shape rather than their segments; she argued that prosody underlies much of word learning at these ages. The fact that the variability of voice fundamental frequency in the spontaneous speech of children 11-25 months old decreases over this age span (Robb \& Saxman, 1985 ) is fully consistent with this analysis.

The problem then seems to be the transition to sentence-level prosody and the coordination of suprasegmental features with lexical and syntactic variations in sentences. There is evidence of children's improved facility in these spheres. For instance, although researchers do not know how early the use of stress emerges in sentence contexts, Allen, Hawkins, and Morris (1979) found that children between 2 and 4 years old change the stress pattern of their utterances as a function of word position in the utterance. Also, Hornby and Hass (1970) found that 4-year-olds use contrastive stress in sentences describing two similar pictures. By age 4 , children implement changes in stress the same way as adults. Thus, they increase the durations of stressed vowels (Smith, 1978) and use changes in intensity of air pressure to mark word stress and position in the sentence (Stathopoulos \& Weismer, 1985). Hence, there is evidence that young children alter suprasegmental features to accommodate variations in sentence structure.

As children become more proficient at sentence planning, they learn to impose suprasegmental features in a more adequate manner, and they need to make fewer alignments of suprasegmental features during online insertions. With practice in sentence production, most children spontaneously recover from stuttering and need no therapeutic intervention. Thus, the spontaneous recovery rate of about $80 \%$ that I noted in my review would seem reasonable in light of the greater proficiency children acquire with sentence production as they mature.

\section{Accounting for Chronic Stuttering}

Why then do some individuals become chronic stutterers? First, the need for SPA is more likely to occur and become chronic in those individuals who are less proficient in their language skills, having either lexical access problems or difficulties with syntactic forms. As I discussed in the review section, stutterers do appear to have deficient receptive and expressive language skills.

One correlate of such a language deficiency is that stutterers require more time for planning their utterances, and the need for more time is manifest both at the point of utterance initiation and during utterance production (Viswanath \& Rosenfield, 1991). The finding that stutterers and nonstutterers do not differ in simple reaction time (e.g., Long \& Pindzola, 1985; Prosek et al., 1979; Till, Reich, Dickey, \& Seiber, 1983; W. G. Webster, 1985) or in VOT on vowel phonation tasks (Cross \& Olson, 1987; Janssen et al., 1983; Murphy \& Baumgartner, 1981; Watson \& Alfonso, 1982) but do differ from nonstutterers on tasks that require lexical accessing or complex syntactic decisions (e.g., Hand \& Haynes, 1983; Rastatter \& Dell, 1987) is consistent with this analysis.

Second, chronic stutterers evidence difficulties in modulating voice fundamental frequency. This difficulty is manifest in several ways, including a greater range of voice fundamental frequency at those points where frequency shifts occur. Nudelman et al. (1989) compared how stutterers and nonstutterers track computer-generated fundamental frequencies by humming. The range of fundamental frequencies evidenced by stutterers was much greater than that of nonstutterers; stutterers exhibited both upward and downward deviations in voice fundamental frequency as compared with the stimulus fundamental frequency.

Moreover, during speech tasks, stutterers evidence both a greater number of voice fundamental frequency inflections and a greater range of voice fundamental frequency than nonstutterers (Healey \& Gutkin, 1984; Lechner, 1979). This pattern is consistent with the fact that greater variability in muscle move- 
ments has been found in stutterers (Denny \& Smith, 1992; Freeman, 1979; Janssen et al., 1983).

The difficulty stutterers have in modulating voice fundamental frequency and their concomitantly deficient language skills jointly underlie the stuttering syndrome. Although it may be tempting to argue that the only problem chronic stutterers have is that of controlling and adjusting voice fundamental frequency, this would be much too simplistic because voice fundamental frequency is not an independent feature of speech. It is a feature that is superimposed on a sentence frame that dictates its contour. The more complex the utterance, the more difficult it is to superimpose a fundamental frequency contour on it (Cooper \& Sorenson, 1981). During spontaneous speech rather than oral reading, it is much more difficult to superimpose a fundamental frequency contour (Hart et al., 1990). The fact that the voice fundamental frequency of stutterers does not differ from that of nonstutterers during reading but does differ during spontaneous speech underlines this last point (Schäfersküpper \& Simon, 1983).

I argue, then, that the need to adjust voice fundamental frequency to accommodate online processes and revisions as spontaneous speech unfolds accounts for chronic stuttering. The finding that the spontaneous repairs of stutterers contain more retracings and longer retracings than those of nonstutterers (Howell, Kadi-Hanifi, \& Young, 1990) is fully consistent with this analysis. In fact, corrections that involve only changes in fundamental frequency but do not involve lexical, syntactic, or conceptual changes seem to be done without any disruption in the flow of speech (Blackmer \& Mitton, 1991). Thus, it is the intricate relationship between sentences and voice fundamental frequency that leads to the complex pattern evident in chronic stutterers.

Why do bilinguals stutter more in their less proficient language? There is some evidence that VOT for the same sounds differs across languages (Flege, 1980, 1992; Flege \& Eefting, 1986; Fourakis \& Iverson, 1984; Lisker \& Abramson, 1964). Flege (1992) argued that realization rules specifying the timing, amplitude, and duration of muscle contractions that position the speech articulators in time and space differ across languages. When the individual acquires a language in which realization rules for given sounds differ, he or she must change the realization rules to match those of the language being acquired. In fact, research has indicated that such a change occurs over time with second language acquisition (Nathan, 1987). Consequently, bilinguals need to make additional decisions involving the motor output system that monolinguals do not need to make.

Because word order and other features of sentences, including suprasegmental features, differ across languages, the need for SPA is more likely to occur in the less proficient of one's languages; the more proficient language may dominate at the point of sentence planning, before morpholexical insertion takes place. Research evidence has indicated that the more proficient language does in fact dominate in terms of various features (Kilborn, 1989; Redlinger \& Park, 1980), including suprasegmental ones (Anderson, 1979; Meisel, 1980). This would necessarily lead to more online revisions in the less proficient language and, hence, necessitate more suprasegmental alignment processes as well.

\section{Accounting for Sentence-Initial Stuttering}

The prevalence of sentence-initial position in stuttering is readily explicable in terms of the SPA model. First, supraseg- mental features of sentences, including the fundamental frequency contour, are determined prior to utterance initiation. Second, as speech unfolds, online processes may dictate changes in some of the suprasegmental features. Yet the need to align suprasegmental plans is most likely to arise at those points at which online processing is most actively engaged. Because the degrees of freedom of morpholexical insertion decrease as more words in the sentence are uttered (Quarrington, 1965; Soderberg, 1967), there is less need to engage in online processes at points further along in the sentence. Thus, people are most likely to engage in online processing at sentence-initial positions rather than in sentence-final positions (Levelt, 1989), as is evident in the greater number of hesitations and filled pauses at early sentence positions (Boomer, 1965). Because online processing may lead to a need for suprasegmental plan revision, moments of stuttering are more likely to occur at sentence-initial positions.

\section{Accounting for Reduced Stuttering During Repeated Readings, Silent Reading, and Whispering}

The finding that stuttering is reduced during repeated readings can be explained within the same framework. With repeated readings, the individual acquires facility with the realization of those suprasegmental features that must be assigned within the passage to be read. Altering the punctuation of a reading passage (which changes the stress pattern and duration of words and phrases) eliminates the advantage of repeated readings and leads to more stuttering rather than less (Wingate, 1966). This result is predictable from the SPA model because changes in punctuation require that a new suprasegmental plan be derived.

The finding that stuttering occurs during silent reading is also interpretable within this framework. Bosshardt and coworkers (Bosshardt, 1990; Bosshardt \& Nandyal, 1988) found that both child and adult stutterers required longer reading times per word and per syllable during both silent and oral reading than did nonstutterers. Moreover, the longer the word, the longer stutterers took to read it silently, whereas for nonstutterers this was not true. These findings are not surprising because both silent speech and whispering are usually accompanied by EMG activity in the speech apparatus even when no movement is observable (Fink, 1975; Sokolov, 1972). Moreover, readers typically report that some form of implicit speech accompanies silent reading (Waters, Komoda, \& Arbuckle, 1985). Items that are longer in duration in vocal speech are also longer in duration in subvocal speech (Smith, Hillenbrand, Wasowicz, \& Preston, 1986). Articulatory processes during silent reading are similarly implicated in Haber and Haber's (1982) finding that tongue twisters take longer to read silently than control sentences.

In the same vein, research has indicated that silent reading involves suprasegmental features, including word stress and sentence accent. Wilding and White (1985) had participants either soundlessly mouth or voice words repetitively (e.g., blabla) while deciding on rhyming of visually presented word pairs. Both conditions significantly increased decision times and led to more errors than hearing the same words said by 
someone else. Foot tapping, on the other hand, did not influence rhyming decisions. Similarly, Campbell, Rosen, Solis-Macias, and White (1991) had participants silently read word pairs and make stress judgments while articulating bla-bla or hearing the same sounds via earphones. Articulating participants made more errors and took longer to make judgments than did participants exposed to the same sounds. Also, when participants read sentences to indicate their stress patterns, saying bla-bla and chewing toffee both impaired accuracy significantly. Thus, silent reading does require assignment of suprasegmental features, and these can be disturbed if the speech apparatus is otherwise occupied at the same time.

Like silent reading, whispering can also lead to stuttering. However, stutterers stutter less during whispering than during voiced speech or reading aloud (e.g., Perkins, Rudas, Johnson, \& Bell, 1976; Venkatagiri, 1981). This is important because whispering, which has no fundamental frequency and does not involve the cricothyroid laryngeal muscle (Vilkman, Raimo, Ignatius, \& Komi, 1987), leads to significant changes in the rhythmic structure of utterances. Bonnot and Chevrie-Muller (1991) found that whispering leads to a significant lengthening of the acoustic duration of consonants. Similarly, Stathopoulos, Hoit, Hixon, Watson, and Solomon (1991) found that whispering leads to a reduction in the number of syllables per breath group. Lehiste (1983) also found that whispering leads to durational changes, with longer pauses at boundaries and some syllabic lengthening. All of these findings imply that whispering may reduce stuttering because it induces rhythmic adjustments, slowing down the rate of production significantly.

\section{Accounting for the Effects of DAF}

The disruptive effects of DAF for nonstutterers and its beneficial effects for stutterers can be accounted for within the same suprasegmental framework. DAF of nonstutterers' speech disrupts the implementation of the suprasegmental speech plan, and such disruption requires alignment processes to be initiated; this can lead to stutterlike symptoms. The fact that the maximal disruption caused by DAF for nonstutterers occurs at about $200 \mathrm{~ms}$ is fully consistent with the findings that the muscles involved in producing suprasegmental features are active between 100 and $200 \mathrm{~ms}$ prior to voicing (Fujimura, 1979). It is not surprising, then, that the main effect of DAF in nonstutterers is to alter the timing of muscle activity as measured by EMG records (Borden, Dorfman, Freeman, \& Raphael, 1977).

From this perspective, the effects of DAF should be no different for the nonstutterer than the effects of white noise (see Howell, 1990). In fact, DAF and white noise both lead to changes in suprasegmental features of speech, including changes in voice fundamental frequency (Brayton \& Conture, 1978; Fairbanks \& Guttman, 1958; Lackner \& Levine, 1975; Lechner, 1979; Ringel \& Steer, 1963) and changes in the duration of words or syllables (Fonagy \& Fonagy, 1966; Ringel \& Steer, 1963). Moreover, there is evidence (Lackner \& Levine, 1975) that when participants know precisely what they are going to say, including both the syntactic and the prosodic intonation required, white noise has no adverse effects on their speech. The fact that the disruptive effects that DAF usually produces in nonstutterers do not occur with very young children in the presyntactic stage (e.g., Yeni-Komshian, Chase, \& Mobley, 1968) or in the production of single words (MacKay, 1987) and the concomitant finding that DAF is more disruptive for 5- and 8-year-old children than for adults (Siegel, Fehst, Garber, \& Pick, 1980) provides further support for this analysis.

Yet the effects of DAF are clearly different from what occurs during a stuttering episode (cf. MacKay, 1987). The disruption of muscle timing under DAF occurs after the onset of voicing, such that speech sounds are either prolonged or started again; inversely, in stuttering, the disruption of muscle timing typically occurs before the onset of voicing (Borden et al., 1977). Howell (1990) found that under DAF disfluencies do not occur at sentence-initial or word-initial positions. Instead, medial vowels are prolonged. Yet almost all stuttering occurs on the initial phoneme of a word. This is especially interesting in light of evidence that some of the effects of DAF reflect attempts to talk during periods of DAF offset and to delay speech during periods of DAF onset (Zimmermann et al., 1988).

Why then does DAF of $400 \mathrm{~ms}$ have a therapeutic effect for stutterers? Because stutterers are slower at all stages of sentence production, this delay allows them to catch up during DAF onset; when their speech is fed back to them, they can better superimpose the suprasegmental plan on the remaining part of the sentence. Voice fundamental frequency can be aligned during periods of DAF onset, when no speech is undertaken and as a result, stutterers evidence greater fluency when they initiate speech again during DAF offset. Consistent with this reasoning, stutterers change both voice fundamental frequency and word duration under white noise (Brayton \& Conture, 1978). Moreover, for stutterers, DAF leads to even more inflectional changes in voice fundamental frequency than do normal feedback conditions. During DAF, however, stutterers produce such inflectional changes at a slower rate than under normal feedback conditions (Lechner, 1979). It would seem, then, that periods of noise or DAF allow alignment processes to take place in stutterers. In fact, Borden and her colleagues (1985) found that some stutterers use periods of blocking for adjusting fundamental frequency.

If stutterers use periods of DAF and white noise to change voice fundamental frequency, then it should be possible to facilitate such changes. If the fundamental frequency with which stutterers attempt to speak is too high, lowering the fundamental frequency of their speech when it is fed back to them should facilitate fluency more than DAF, which only allows for adjustments to be made. In contrast, raising the fundamental frequency of their speech when it is fed back should be no more facilitative than DAF because the raised frequency of the feedback should not help them lower the fundamental frequency of the remaining part of the utterance. For nonstutterers, either raising or lowering voice fundamental frequency should be as detrimental to fluency as DAF because it constitutes noise in either case. Although this prediction has not been tested directly, two studies have provided support for it. Howell, El Yaniv, and Powell (1987) found that feedback that had been frequency-shifted downward (by one octave) facilitated fluency more than DAF in stutterers. Moreover, frequency shifting only at syllable onset was less conducive to fluency than when all speech was frequency shifted. Yet feedback that had been frequency-shifted upward (by half an octave) was recently found to be no different than DAF in its effects on fluency 
(Kalinowski, Armson, Roland-Mieszkowski, Stuart, \& Gracco, 1993). Although the effect of frequency shifting has not been examined in nonstutterers, this pattern of data is fully supportive of my analysis of the effects of DAF.

\section{Non-Language-Based Therapeutic Techniques}

From the perspective of the current model, therapeutic techniques may be two pronged. First, they may focus on improving language skills. Second, such techniques may incorporate variations in speaking that either slow down the rhythm (thereby slowing rate of output and reducing the need to coarticulate) or reduce the likelihood that a need for SPA will arise. In fact, the techniques that have been found to be successful in reducing stuttering (e.g., Andrews et al., 1980, 1983) appear to be ones that change either the rhythmic or the melodic structure of the utterance. For instance, speech therapy using precision shaping (R. L. Webster, 1974) reduces the variability of voice fundamental frequency in treated participants (Franken, 1987). In metronome pacing, stutterers slow down their rate of speech to synchronize with the beat of a metronome or an auditory tone, usually at a rate of one beat per second. The technique is fluency enhancing (Hutchinson \& Norris, 1977; Van Riper, 1971) but leads to changes in many suprasegmental features of speech, including vowel lengthening (Brayton \& Conture, 1978). It apparently reduces the need for coarticulation and changes the fundamental frequency contour of utterances. Hence, its impact on stuttering rate is consistent with my predictions. According to the current model, any technique that alters the rate of speech production and reduces the likelihood that SPA will be required should reduce stuttering. Thus, the reduction in stuttering during singing (Wingate, 1988) and praying ${ }^{5}$ is also consistent with the model.

\section{Conclusions}

My review of stuttering indicated that although cognitive and linguistic factors are an integral part of the stuttering syndrome; models of stuttering have not accounted for the complex pattern in which stuttering is manifest. I have presented a model of stuttering within the context of sentence-production processes. In this model, the suprasegmental features assigned prior to initiating an utterance often need to be changed as a consequence of online sentence production processes that may implicate changes in these features. The need to align the original suprasegmental plan with the revised suprasegmental plan results in moments of disfluency in both stuttering and nonstuttering individuals. The SPA model parsimoniously accounts for the majority of findings in the stuttering literature and is generally consistent with models of speech production (e.g., Garrett, 1975; Levelt, 1989).

Finally, my formulation of the stuttering moment has important empirical and therapeutic implications that have not been raised in the context of existing models. For instance, I would predict that exposing stutterers to the fundamental frequency contour of the to-be-uttered sentence, a technique used in second language training (e.g., Anderson, 1979), will be fluency enhancing and less disturbing to stutterers' speech pattern than are other therapeutic techniques. This possibility and other im- plications of the SPA model will have to be examined in future research.

${ }^{5}$ I would like to thank Iris Levin of Tel Aviv University for bringing
his point to my attention.

\section{References}

Adams, M. R. (1982). Fluency, nonfluency, and stuttering in children. Journal of Fluency Disorders, 7, 171-185.

Adams, M. R. (1987). Voice onsets and segment durations of normal speakers and beginning stutterers. Journal of Fluency Disorders, 12, 133-139.

Adams, M. R. (1990). The demands and capacities model I: Theoretical elaborations. Journal of Fluency Disorders, 15, 135-141.

Allen, G. D., \& Hawkins, S. (1980). Phonological rhythm: Definition and development. In G. A. Yeni-Komshian, J. F. Kavanagh, \& C. A. Ferguson (Eds.), Child phonology: Vol. 1. Production (pp. 227-256). New York: Academic Press.

Allen, G. D., Hawkins, S., \& Morris, M. R. (1979). Development of "nuclear accent" marking in children's phrases. In H. Hollien \& P. Hollien (Eds.), Current issues in the phonetic sciences II (pp. 919926). Amsterdam: John Benjamins.

Anderson, K. O. (1979). Applied prosodic analysis: A pedagogical model for English and German intonation. In H. Hollien \& P. Hollien (Eds.), Current issues in the phonetic sciences I (pp. 227-234). Amsterdam: John Benjamins.

Andrews, G., Craig, A., Feyer, A.-M., Hoddinott, S., Howie, P., \& Neilson, M. (1983). Stuttering: A review of research findings and theories circa 1982. Journal of Speech and Hearing Disorders, 48, 226-246.

Andrews, G., Guitar, B., \& Howie, P. (1980). Meta-analysis of the effects of stuttering treatment. Journal of Speech and Hearing Research, 45, 287-307.

Andrews, G., \& Harris, M. (1964). The syndrome of stuttering. London: Heinemann Books.

Azrin, N. H., \& Nunn, R. G. (1974). A rapid method of eliminating stuttering by a regulated breathing approach. Behavior Research and Therapy, 12, 279-286.

Beardsley, A. N., \& Cullinan, W. L. (1987). Speech sample type and children's segmental durations. Journal of Phonetics, 15, 29-38.

Beattie, G. W. (1980). Encoding units in spontaneous speech: Some implications for the dynamics of conversation. In $\mathbf{H}$. W. Dechert \& M. Raupach (Eds.), Temporal variables in speech. The Hague, The Netherlands: Mouton.

Bergmann, G. (1986). Studies in stuttering as a prosodic disturbance. Journal of Speech and Hearing Research, 29, 290-300.

Bernstein, N. E. (1981). Are there constraints on childhood disfluency? Journal of Fluency Disorders, 6, 341-350.

Blackmer, E. R., \& Mitton, J. L. (1991). Theories of monitoring and the timing of repairs in spontaneous speech. Cognition, 39, 173-194.

Blood, G. W., \& Hood, S. B. (1978). Elementary school-aged stutterers' disfluencies during oral reading and spontaneous speech. Journal of Fluency Disorders, 3, 155-165.

Bloodstein, O. (1993). Stuttering: The search for a cause and a cure. Boston: Allyn \& Bacon.

Bloodstein, O., \& Grossman, M. (1981). Early stuttering: Some aspects of their form and distribution. Journal of Speech and Hearing Research, 24, 298-302.

Bloom, L. (1973). One word at a time. The Hague, The Netherlands: Mouton.

Bock, J. K. (1986). Meaning, sound, and syntax: Lexical priming in sentence production. Journal of Experimental Psychology: Learning, Memory, and Cognition, 12, 119-137.

Bock, K. (1987a). An effect of the accessibility of word forms on sentence structures. Journal of Memory and Language, 26, 119-137. 
Bock, K. (1987b). Exploring levels of processing in sentence production. In G. Kempen (Ed.), Natural language generation: New results in artificial intelligence, psychology and linguistics (pp. 351-363). Dordrecht, The Netherlands: Martinus Nijhoff.

Bonnot, J.-F. P., \& Chevrie-Muller, C. (1991). Some effects of voiced and whispered conditions on temporal organization. Journal of Phonetics, 19, 473-483.

Boomer, D. S. (1965). Hesitation and grammatical encoding. Language and Speech, 8, 148-158.

Borden, G. J., Baer, T., \& Kenney, M. K. (1985). Onset of voicing in stuttered and fluent utterances. Journal of Speech and Hearing Research, 28, 363-372.

Borden, G. J., Dorfman, M. F., Freeman, F. J., \& Raphael, L. J. (1977). Electromyographic changes with delayed auditory feedback of speech. Journal of Phonetics, 5, 1-8.

Bosshardt, H.-G. (1990). Subvocalization and reading rate differences between stuttering and nonstuttering children and adults. Journal of Speech and Hearing Research, 33, 776-778.

Bosshardt, H.-G., \& Nandyal, I. (1988). Reading rates of stutterers and nonstutterers during silent and oral reading. Journal of Fluency Disorders, $13,407-420$

Branigan, G. (1979). Some reasons why successive single word utterances are not. Journal of Child Language, 6, 411-421.

Branigan, G., \& Stokes, W. (1984). An integrated account of utterance variability in early language development. In C. L. Thew \& C. E. Johnson (Eds.), Proceedings of the Second International Congress for the Study of Child Language, Vol. 2 (pp. 73-88). Lanham, MD: University Press of America.

Brayton, E. R., \& Conture, E. G. (1978). Effects of noise and rhythmic stimulation on the speech of stutterers. Journal of Speech and Hearing Research, 21, 285-294.

Brazil, D. (1984). The intonation of sentences read aloud. In D. Gibbon \& H. Richter (Eds.), Intonation, accent, and rhythm: Studies in discourse phonology (pp. 46-66). New York: Walter de Gruyter.

Brown, R. (1973). A first language: The early stages. Cambridge, MA: Harvard University Press.

Brutten, G. J., \& Hedge, M. N. (1984). Stuttering: A clinically-related overview. In S. Dickson (Ed.), Communication disorders. Glenview, IL: Scott Foresman.

Brutten, G. J., \& Trotter, A. C. (1986). A dual-task investigation of young stutterers and nonstutterers. Journal of Fluency Disorders, 11 , 275-284.

Butterworth, B. (1980). Evidence from pauses in speech. In B. Butterworth (Ed.), Language production: Vol. 1. Speech and talk (pp. 155176). London: Academic Press.

Byrd, K., \& Cooper, E. B. (1989). Expressive and receptive language skills in stuttering children. Journal of Fluency Disorders, 14, 121126.

Campbell, R., Rosen, S., Solis-Macias, V., \& White, T. (1991). Stress in silent reading: Effects of concurrent articulation on the detection of syllabic stress patterns in written words in English speakers. Language and Cognitive Processes, 6, 29-47.

Caruso, A. J., Conture, E. G., \& Colton, R. H. (1988). Selected temporal parameters of coordination associated with stuttering in children. Journal of Fluency Disorders, 13, 57-82.

Cecconi, C., Hood, S. B., \& Tucker, R. K. (1977). Influence of reading level difficulty on the disfluencies of normal children. Journal of Speech and Hearing Research, 20, 475-484.

Colburn, N., \& Mysak, E. D. (1982a). Developmental disfluency and emerging grammar: I. Disfluency characteristics in early syntactic utterances. Journal of Speech and Hearing Research, 25, 414-420.

Colburn, N., \& Mysak, E. D. (1982b). Developmental disfluency and emerging grammar: II. Co-occurrence of disfluency with specified se- mantic-syntactic structures. Journal of Speech and Hearing Research, 25, 421-427.

Conture, E. G. (1991). Young stutterers' speech production: A critical review. In H. F. M. Peters, W. Hulstijn, \& C. W. Starkweather (Eds.), Speech motor control and stuttering (pp. 365-384). New York: Elsevier.

Conture, E. G., Colton, R. H., \& Gleason, J. R. (1988). Selected temporal aspects of coordination during fluent speech of stutterers and nonstutterers. Journal of Speech and Hearing Research, 31, 640-653.

Cooper, W. E. (1980). Syntactic-to-phonetic encoding. In B. Butterworth (Ed.), Language production: Vol. 1. Speech and talk (pp. $297-$ 333). London: Academic Press.

Cooper, W. E., \& Sorenson, J. M. (1981). Fundamental frequency in sentence production. New York: Springer-Verlag.

Cross, D. E., \& Luper, H. L. (1979). Voice reaction time of stuttering and nonstuttering children and adults. Journal of Fluency Disorders, 4, 59-77.

Cross, D. E., \& Olson, P. (1987). Interaction between jaw kinematics and voice onset for stutterers and nonstutterers in a VRT task. Journal of Fluency Disorders, 12, 367-380.

Cross, D. E., Shadden, B. B., \& Luper, H. L. (1979). Effects of stimulus ear presentation on the voice reaction time of adult stutterers and nonstutterers. Journal of Fluency Disorders, 4, 45-58.

Crystal, D., Fletcher, P., \& Garman, M. (1976). The grammatical analysis of language disability. London: Edward Arnold.

Cullinan, W., \& Springer, M. T. (1980). Voice initiation and termination times in stuttering and nonstuttering children. Journal of Speech and Hearing Research, 23, 344-360.

Cutier, A. (1980). Errors of stress and intonation. In V. A. Fromkin (Ed.), Errors in linguistic performance (pp. 67-80). New York: Academic Press.

Cutler, A. (1983). Speakers' conceptions of the function of prosody. In A. Cutler \& D. R. Ladd (Eds.), Prosody: Models and measurements (pp. 79-91). New York: Springer-Verlag.

Cutler, A. (1984). Stress and accent in language production and understanding. In D. Gibbon \& H. Richter (Eds.), Intonation, accent, and rhythm: Studies in discourse phonology (pp. 77-90). New York: Walter de Gruyter.

Dale, P. (1977). Factors related to disfluent speech in bilingual Cuban American adolescents. Journal of Fluency Disorders, 2, 311-314.

Deese, J. (1980). Pauses, prosody, and the demands of production in language. In H. W. Dechert \& M. Raupach (Eds.), Temporal variables in speech (pp. 69-84). The Hague, The Netherlands: Mouton.

Denny, M., \& Smith, A. (1992). Gradations in a pattern of neuromuscular activity associated with stuttering. Journal of Speech and Hearing Research, 35, 1216-1229.

De Smedt, K., \& Kempen, G. (1987). Incremental sentence production, self correction and coordination. In G. Kempen (Ed.), Natural language generation: New result in artificial intelligence, psychology and linguistics (pp. 365-376). Dordrecht, The Netherlands: Martinus Nijhoff.

Echols, C. H. (1993). A perceptually based model of children's earliest productions. Cognition, 46, 245-296.

Eisenson, J. (1984). Stuttering as an expression of inefficient language development. In L. J. Raphael, C. B. Raphael, \& M. R. Vasovinos (Eds.), Language and cognition: Essays in honor of Arthur Bronstein (pp. 59-72). New York: Plenum Press.

Eisenson, J. (1986). Language and speech disorders in children. New York: Pergamon Press.

Fairbanks, G., \& Guttman, M. (1958). Effects of delayed auditory feedback upon articulation. Journal of Speech and Hearing Research, 1 , 12-22.

Falck, F. J., Lawler, P. S., \& Yonovitz, A. (1985). Effects of stuttering on fundamental frequency. Journal of Fluency Disorders, 10, 123-135. 
Farnetani, E., \& Kori, S. (1986). Effects of syllable and word structure on segmental durations in speaking Italian. Speech Communication, 5, 17-34.

Fink, B. R. (1975). The human larynx: A functional study. New York: Raven Press.

Flege, J. E. (1980). Phonetic approximation in second language acquisition. Language Learning, 30, 117-134.

Flege, J. E. (1983). The influence of stress, position, and utterance length on the pressure characteristics of English /p/ and /b/. Journal of Speech and Hearing Research, 26, 111-118.

Flege, J. E. (1992). The intelligibility of English vowels spoken by British and Dutch talkers. In R. D. Kent (Ed.), Intelligibility in speech disorders: Theory, measurement and management (pp. 157-232). Amsterdam: John Benjamins.

Flege, J. E., \& Eefting, W. (1986). Linguistic and developmental effects on the production and perception of stop consonants. Phonetica, 43, 155-171.

Folkins, J. W. (1991). Stuttering from a speech motor control perspective. In H. F. M. Peters, W. Hulstijn, \& C. W. Starkweather (Eds.), Speech motor control and stuttering (pp. 561-570). New York: Elsevier.

Fonagy, I., \& Fonagy, J. (1966). Sound pressure level and duration. Phonetica, 15, 14-21.

Ford, M. (1982). Sentence planning units: Implications for the speaker's representation of meaningful relations underlying sentences. In $\mathbf{J}$. Bresnan (Ed.), The mental representation of grammatical relations (pp. 797-827). Cambridge, MA: MIT Press.

Ford, M., \& Holmes, V. M. (1978). Planning units and syntax in sentence production. Cognition, 6, 35-53.

Fourakis, M., \& Iverson, G. K. (1984). On the acquisition of second language timing patterns. Language Learning, 5, 323-347.

Franken, M. C. (1987). Perceptual and acoustic evaluation of stuttering therapy. In H. F. M. Peters \& W. Hulstijn (Eds.), Speech motor $d y$ namics in stuttering. New York: Springer-Verlag.

Freeman, F. J. (1975). Phonation and fluency. In M. Webster \& L. Furst (Eds.), Vocal tract dynamics and disfluency. New York: Speech \& Hearing Institute.

Freeman, F. J. (1979). Phonation in stuttering: A review of current research. Journal of Fluency Disorders, 4, 79-89.

Fromkin, V. A. (1971). The nonanomalous nature of anomalous utterances. Language, 47, 27-52.

Fuchs, A. (1984). "Deaccenting" and "default accent." In D. Gibbon \& H. Richter (Eds.), Intonation, accent, and rhythm: Studies in discourse phonology (pp. 134-164). New York: Walter de Gruyter.

Fujimura, O. (1979). Physiological functions of the larynx in phonetic control. In H. Hollien \& P. Hollien (Eds.), Current issues in the phonetic sciences I (pp. 129-163). Amsterdam: John Benjamins.

Fujimura, O. (1981). Temporal organization of articulatory movements as a multidimensional phrasal structure. Phonetica, 38, 66-83.

Fujimura, O. (1986). Relative invariance of articulatory movements: An iceberg model. In J. S. Perkell \& D. H. Klatt (Eds.), Invariance and variability in speech processes (pp. 226-252). Hillsdale, NJ: Erlbaum.

Gaines, N., Runyan, C. M., \& Meyers, S. C. (1991). A comparison of young stutterers' fluent versus stuttered utterances on measures of length and complexity. Journal of Speech and Hearing Research, 34, 37-42.

Garber, S. R., \& Siegel, G. M. (1982). Feedback and motor control in stuttering. In D. K. Routh (Ed.), Learning, speech and the complex effects of punishment (pp. 93-123). New York: Plenum Press.

Garrett, M. F. (1975). The analysis of sentence production. In G. C. Bower (Ed.), The psychology of learning and motivation (Vol. 9, pp. 133-177). New York: Academic Press.

Garrett, M. F. (1980). Levels of processing in sentence production. In
B. Butterworth (Ed.), Language production: Vol. 1. Speech and talk (pp. 177-220). London: Academic Press.

Garro, L., \& Parker, F. (1982). Some suprasegmental characteristics of relative clauses in English. Journal of Phonetics, 10, 149-161.

Garro, L., \& Parker, F. (1983). Relative clauses in Spanish: Some suprasegmental characteristics. Journal of Phonetics, 11, 85-99.

Good, D. A., \& Butterworth, B. (1980). Hesitancy as a conversational resource: Some methodological implications. In H. G. Dechert \& M. Raupach (Eds.), Temporal variables in speech (pp. 145-152). The Hague, The Netherlands: Mouton.

Gordon, P. A., \& Luper, H. L. (1989). Speech disfluencies in nonstutterers: Syntactic complexity and production task effects. Journal of Fluency Disorders, 14, 429-445.

Gordon, P. A., Luper, H. L., \& Peterson, H. A. (1986). The effects of syntactic complexity on the occurrence of disfluencies in 5-year-old nonstutterers. Journal of Fluency Disorders, 11, 151-164.

Greiner, J. R., Fitzgerald, H. E., \& Cooke, P. A. (1986). Speech fluency and hand preference on a sequential tapping task in left- and righthanded stutterers and nonstutterers. Journal of Fluency Disorders, $11,55-69$.

Haber, L. R., \& Haber, R. N. (1982). Does silent reading involve articulation? Evidence from tongue twisters. American Journal of Psychology, 95, 409-419.

Halle, M. (1985). Speculations about the representation of words in memory. In V. A. Fromkin (Ed.), Phonetic linguistics (pp. 101-114). Orlando, FL: Academic Press.

Hamre, C. E., \& Wingate, M. E. (1973). Stuttering consistency in varied contexts. Journal of Speech and Hearing Research, 16, 238-247.

Hand, C. R., \& Haynes, W. O. (1983). Linguistic processing and reaction time differences in stutterers and nonstutterers. Journal of Speech and Hearing Research, 26, 181-185.

Hart, J.'T., Collier, R., \& Cohen, A. (1990). A perceptual study of intonation. Cambridge, England: Cambridge University Press.

Healey, E. C., \& Bernstein, B. (1991). Acoustic analyses of young stutterers' and nonstutterers' disfluencies. In H. F. M. Peters, W. Hulstijn, \& C. W. Starkweather (Eds.), Speech motor control and stuttering (pp. 401-407). New York: Elsevier.

Healey, E. C., \& Gutkin, B. (1984). Analysis of stutterers' voice onset times and fundamental frequency contours during fluency. Journal of Speech and Hearing Research, 27, 219-225.

Hedge, M. N. (1982). Antecedents of fluent and dysfluent oral reading: A descriptive analysis. Journal of Fluency Disorders, 7, 323-341.

Hirano, M., Ohala, J., \& Vennard, W. (1969). The function of laryngeal muscles in regulating fundamental frequency and intensity of phonation. Journal of Speech and Hearing Research, 12, 616-628.

Hockett, C. F. (1973). Where the tongue slips, there slip I. In V. A. Fromkin (Ed.), Speech errors as linguistic evidence (pp. 93-119). The Hague, The Netherlands: Mouton.

Hornby, P. A., \& Hass, W. A. (1970). Use of contrastive stress by preschool children. Journal of Speech and Hearing Research, 13, 395399.

Howell, P. (1990). Changes in voice level caused by several forms of altered feedback in fluent speakers and stutterers. Language and Speech, 33, 325-338.

Howell, P., El Yaniv, N., \& Powell, D. J. (1987). Factors affecting fluency in stutterers when speaking under auditory feedback. In H. F. M. Peters \& W. Hulstijn (Eds.), Speech motor dynamics in stuttering (pp. 361-369). New York: Springer-Verlag.

Howell, P., Kadi-Hanifi, K., \& Young, K. (1990). Phrase repetitions in fluent and stuttering children. In H. F. M. Peters, W. Hulstijn, \& C. W. Starkweather (Eds.), Speech motor control and stuttering (pp. 415-422). New York: Elsevier.

Howell, P., \& Williams, M. (1992). Acoustic analysis and perception of 
vowels in children's and teenagers' stuttered speech. Journal of the Acoustical Society of America, 91, 1697-1706.

Hutchinson, J. M., \& Norris, G. M. (1977). The differential effect of three auditory stimuli on the frequency of stuttering behaviors. Journal of Fluency Disorders, 2, 283-293.

Ingham, R. J., Southwood, H., \& Hersburgh, G. (1981). Some effects of the Edinburgh Masker on stuttering during reading and spontaneous speech. Journal of Fluency Disorders, 6, 135-154.

Jaeger, J. J. (1992). "Not by the chair of my hinny hin hin:" Some general properties of slips of the tongue in young children. Journal of Child Language, 19, 335-366.

Janssen, P., Wieneke, G., \& Vaane, E. (1983). Variability in the initiation of articulatory movements in the speech of stutterers and normal speakers. Journal of Fluency Disorders, 8, 341-358.

Jayaram, M. (1984). Distribution of stuttering in sentences: Relationship to sentence length and clause position. Journal of Speech and Hearing Research, 27, 338-341.

Johnson, W. (1955). A study of the onset and development of stuttering. In W. Johnson \& R. Leutenegger (Eds.), Stuttering in children and adults. Minneapolis: University of Minnesota Press.

Johnson, W. (1961). Measurements of oral reading and speaking rate and disfluency of adult male and female stutterers and nonstutterers. Journal of Speech and Hearing Disorders, 26(Monograph Suppl. 7), $1-20$.

Kalinowski, J., Armson, J., Roland-Mieszkowski, M., Stuart, A., \& Gracco, V. L. (1993). Effects of alterations in auditory feedback and speech rate on stuttering frequency. Language and Speech, 36, 1-16.

Karniol, R. (1992). Stuttering out of bilingualism. First Language, 12, 255-283.

Kempen, G., \& Hoenkamp, E. (1987). An incremental procedural grammar for sentence formulation. Cognitive Science, 11, 201-258.

Kent, R. D. (1983a). Facts about stuttering: Neuropsychologic perspectives. Journal of Speech and Hearing Disorders, 48, 249-255.

Kent, R. D. (1983b). The segmental organization of speech. In P. F. MacNeilage (Ed.), The production of speech (pp. 57-89). New York: Springer-Verlag.

Kent, R. D., \& Minifie, F. D. (1977). Coarticulation in recent speech production models..Journal of Phonetics, 5, 115-133.

Kent, R. D., \& Netsell, R. (1971). Effects of stress contrasts on certain articulatory parameters. Phonetica, 24, 23-47.

Kilborn, K. (1989). Sentence processing in a second language: The timing of transfer. Language and Speech, 32, 1-23.

Kolk, H. (1991). Is stuttering a symptom of adaptation or impairment? In H. F. M. Peters, W. Hulstijn, \& C. W. Starkweather (Eds.), Speech motor control and stuttering (pp. 131-140). New York: Elsevier.

Konefal, J. A., \& Fokes, J. (1985). Acoustic analysis of children's conversational repairs. Journal of Phonetics, 13, 97-105.

Konefal, J. A., Fokes, J., \& Bond, Z. S. (1982). Children's syntactic use of vowel duration. Journal of Phonetics, 10, 361-366.

Koopmans, M., Slis, I., \& Rietveld, T. (1991). The influence of word position and word type on the incidence of stuttering. In H. F. M. Peters, W. Hulstijn, \& C. W. Starkweather (Eds.), Speech motor control and stuttering (pp. 333-340). New York: Elsevier.

Kowal, S., O'Connell, D., \& Sabin, E. J. (1975). Development of temporal patterning and vocal hesitations in spontaneous narratives. Journal of Psycholinguistic Research, 4, 195-207.

Kubaska, C. A., \& Keating, P. A. (1981). Word duration in early child speech. Journal of Speech and Hearing Research, 24, 615-621.

Lackner, J., \& Levine, K. B. (1975). Speech production: Evidence for syntactically and phonologically determined units. Perception and Psychophysics, 17, 107-113.

Laver, J. D. M. (1973). The detection and correction of slips of the tongue. In V. A. Fromkin (Ed.), Speech errors as linguistic evidence (pp. 132-143). The Hague, The Netherlands: Mouton.
Laver, J. D. M. (1980). Monitoring systems in the neurolinguistic control of speech production. In V. A. Fromkin (Ed.), Errors in linguistic performance (pp. 287-305). New York: Academic Press.

Lechner, B. K. (1979). Effects of delayed auditory feedback and masking on the fundamental frequency of stutterers and nonstutterers. Journal of Speech and Hearing Research, 22, 343-353.

Lehiste, I. (1970). Suprasegmentals. Cambridge, MA: MIT Press.

Lehiste, I. (1980). Interaction between test word duration and length of utterance. In L. R. Waugh \& C. H. van Schooneveld (Eds.), The melody of language (pp. 169-176). Baltimore: University Park Press.

Lehiste, I. (1983). Signalling of syntactic structure in whispered speech. Folia Linguistica, 17, 239-246.

Lehiste, I., \& Ivic, P. (1986). Word and sentence prosody in Serbo-Croatian. Cambridge, MA: MIT Press.

Levelt, W., \& Maassen, B. (1981). Lexical search and order of mention in sentence production. In W. Klein \& W. Levelt (Eds.), Crossing the boundaries in linguistics (pp. 221-252). Dordrecht, The Netherlands: D. Reidel.

Levelt, W. J. M. (1983). Monitoring and self repair in speech. Cognition, 14, 41-104.

Levelt, W. J. M. (1989). Speaking: From intention to articulation. Cambridge, MA: MIT Press.

Lieberman, P. (1967). Intonation, perception and language. Cambridge, MA: MIT Press.

Lindsley, J. R. (1975). Producing simple utterances: How far ahead do we plan? Cognitive Psychology, 7, 1-19.

Lindsley, J. R. (1976). Producing simple utterances: Details of the planning process. Journal of Psycholinguistic Research, 5, 331-354.

Lisker, L., \& Abramson, A. S. (1964). A cross-linguistic study of voicing of initial stops: Acoustical measurements. Word, 20, 384-422.

Long, K. M., \& Pindzola, R. H. (1985). Manual reaction time to linguistic stimuli in child stutterers and nonstutterers. Journal of Fluency Disorders, 10, 143-149.

Lubker, J. (1981). Temporal aspects of speech production: Anticipatory labial coarticulation. Phonetica, 38, 51-65.

Lyberg, B. (1977). Some observations on the timing of Swedish utterances. Journal of Phonetics, 5, 49-59.

MacKay, D. G. (1966). To end ambiguous sentences. Perception and Psychophysics, I, 426-536.

MacKay, D. G. (1987). The organization and perception of action: $A$ theory for language and other cognitive skills. New York: SpringerVerlag.

MacKay, D. G., \& Bowman, D. (1969). On producing the meaning in sentences. American Journal of Psychology, 69, 77-1 10.

MacKay, D. G., \& MacDonald, M. C. (1984). Stuttering as a sequencing and timing disorder. In R. F. Curlee \& W. H. Perkins (Eds.), Nature and treatment of stuttering: New directions. San Diego, CA: College Hill Press.

MacNeilage, P. F. (1980). Distinctive properties of speech motor control. In G. E. Stelmach \& J. Requin (Eds.), Tutorials in motor behavior (pp. 607-621). Amsterdam: North-Holland.

MacNeilage, P. F. (1981). Feedback in speech production: An ecological perspective. In T. Myers, J. Laver, \& J. Anderson (Eds.), The cognitive representation of speech (pp. 39-44). Amsterdam: North-Holland.

Mattes, L. J., \& Omark, D. R. (1984). Speech and language assessment for the bilingual handicapped. San Diego, CA: College Hill Press.

McGee, S. R., Hutchinson, J. M., \& Deputy, P. N. (1981). The influence of the onset of phonation on the frequency of disfluency among children who stutter. Journal of Speech and Hearing Research, 24, 269 272.

Meisel, J. M. (1980). Linguistic simplification. In S. W. Felix (Ed.), Second language development: Trends and issues ( $\mathrm{pp} .13-40$ ). Tübingen, Germany: Narr. 
Menyuk, P. (1969). Sentences children use. Cambridge, MA: MIT Press.

Menyuk, P., \& Klatt, M. (1975). Voice onset time in consonant cluster production by children and adults. Journal of Child Language, 2, 223-231.

Molt, L. F. (1991). Selected acoustic and physiologic measures of speech motor coordination in stuttering and nonstuttering children. In H. F. M. Peters, W. Hulstijn, \& C. W. Starkweather (Eds.), Speech motor control and stuttering (pp. 433-439). New York: Elsevier.

Moore, W. H. (1978). Some effects of progressively lowering electromyographic levels with feedback procedures on the frequency of stutterers' verbal behaviors. Journal of Fluency Disorders, 3, 127-138.

Motley, M. T., \& Baars, B. J. (1979). Effects of cognitive set upon laboratory induced verbal (Freudian) slips. Journal of Speech and Hearing Research, 22, 421-432.

Murphy, M., \& Baumgartner, J. M. (1981). Voice initiation and termination time in stuttering and nonstuttering children. Journal of Fluency Disorders, 6, 257-264.

Murray, H. L., \& Reed, C. G. (1977). Language abilities of preschpol stuttering children. Journal of Fluency Disorders, 2, 171-176.

Nathan, G. S. (1987). On second language acquisition of voiced stops. Journal of Phonetics, 15, 313-322.

Nippold, M. A. (1990). Concomitant speech and language disorders in stuttering children: A critique of the literature. Journal of Speech and Hearing Disorders, 55, 51-60.

Nooteboom, S. G. (1980). Speaking and unspeaking: Detection and correction of phonological and lexical errors in spontaneous speech. In V. A. Fromkin (Ed.), Errors in linguistic performance (pp. 87-95). New York: Academic Press.

Nudelman, H. B., Herbrich, K. E., Hoyt, B. D., \& Rosenfield, D. B. (1989). A neuroscience model of stuttering. Journal of Fluency Disorders, 14, 399-427.

Nwokah, E. E. (1988). The imbalance of stuttering behavior in bilingual speakers. Journal of Fluency Disorders, 13, 357-373.

Palen, C., \& Peterson, J. M. (1982). Word frequency and children's stuttering: The relationship to sentence structure. Journal of Fluency Disorders, 7, 55-62.

Panelli, C. A., McFarlane, S. C., \& Shipley, K. G. (1978). Implications of evaluating and intervening with incipient stutterers. Journal of Fluency Disorders, 2, 41-50.

Pearl, S. Z., \& Bernthal, J. E. (1980). The effect of grammatical complexity upon disfluency behavior of nonstuttering preschool children. Journal of Fluency Disorders, 5, 55-68.

Perkins, W., Rudas, J., Johnson, L., \& Bell, J. (1976). Stuttering: Discoordination of phonation with articulation and respiration. Journal of Speech and Hearing Research, 19, 509-522.

Perkins, W. H., Kent, R. D., \& Curlee, R. F. (1991). A theory of neuropsycholinguistic function in stuttering. Journal of Speech and Hearing Research, 34, 734-752.

Peters, H. F. M., Hulstijn, W., \& Starkweather, C. W. (1989). Acoustic and physiological reaction times of stutterers and nonstutterers. Journal of Speech and Hearing Research, 32, 668-680.

Peters, H. F. M., \& Starkweather, C. W. (1990). The interaction between speech motor coordination and language processes in the development of stuttering: Hypotheses and suggestions for research. Journal of Fluency Disorders, 15, 115-125.

Pratt, J. E. (1984). An analysis of linguistic perception in preschool stutterers and nonstutterers. In R. G. Daniloff (Ed.), Articulation assessment and treatment issues (pp. 269-278). San Diego, CA: College Hill Press.

Prins, D. (1991). Theories of stuttering as event and disorder: Implications for speech production processes. In H. F. M. Peters, W. Hulstijn, \& C. W. Starkweather (Eds.), Speech motor control and stuttering (pp. 571-580). New York: Elsevier.
Prins, D., Hubbard, C. P., \& Krause, M. (1991). Syllabic stress and the occurrence of stuttering. Journal of Speech and Hearing Research, 34, 1011-1016.

Prosek, R., Montgomery, A. A., Walden, B. F., \& Schwartz, D. M. (1979). Reaction time measures of stutterers and nonstutterers. Journal of Fluency Disorders, 4, 269-278.

Quarrington, B. (1965). Stuttering as a function of the information value and sentence position of words. Journal of Abnormal Psychology, 70, 221-224.

Quarrington, B., Conway, J., \& Siegel, N. (1962). An experimental study of some properties of stuttered words. Journal of Speech and Hearing Research, 5, 387-394.

Rastatter, M. P., \& Dell, C. W. (1987). Simple visual versus lexical decision vocal reaction times of stuttering and normal subjects. Journal of Fluency Disorders, 12, 63-70.

Ratner, N. B., \& Benitez, M. (1985). Linguistic analysis of a bilingual stutterer. Journal of Fluency Disorders, 10, 211-219.

Ratner, N. B., \& Sih, C. C. (1987). Effects of gradual increases in sentence length and complexity on children's disfluency. Journal of Speech and Hearing Disorders, 52, 278-287.

Redlinger, W. E., \& Park, T. Z. (1980). Language mixing in young bilinguals. Journal of Child Language, 7, 337-352.

Riley, G., \& Riley, J. (1979). A component model for diagnosing and treating children who stutter. Journal of Fluency Disorders, 4, 279294.

Ringel, R. L., \& Steer, M. D. (1963). Some effects of tactile and auditory alterations on speech output. Journal of Speech and Hearing Research, 6, 369-378.

Robb, M. P., \& Saxman, J. H. (1985). Developmental trends in vocal fundamental frequency of young children. Journal of Speech and Hearing Research, 28, 421-427.

Rosenfield, D. B., \& Nudelman, H. B. (1987). Neuropsychologic models of speech dysfluency. In L. Rustin, H. Purser, \& D. Rowley (Eds.), Progress in the treatment of fluency disorders. New York: Taylor \& Francis.

Runyan, C. M., \& Bonifant, D. C. (1981). A perceptual comparison: All voiced versus typical reading passage read by children. Journal of Fluency Disorders, 6, 247-255.

Ryan, B. (1974). Programmed therapy for stuttering in children and adults. Springfield, IL: Charles C Thomas.

Ryan, B. P. (1992). Articulation, language rate, and fluency characteristics of stuttering and nonstuttering preschool children. Journal of Speech and Hearing Research, 35, 333-342.

Sabin, E. J., Clemmer, E. J., O'Connell, D. C., \& Kowal, S. (1979). A pausological approach to speech development. In A. W. Siegman \& S. Feldstein (Eds.), Of speech and time (pp. 35-55). Hillsdale, NJ: Erlbaum.

St. Louis, K. D., Hintzman, A. R., \& Hull, F. M. (1985). Studies of cluttering: Disfluency and language measures in young possible clutterers and stutterers. Journal of Fluency Disorders, 10, 151-172.

Schaferskupper, P., \& Simon, T. (1983). The mean fundamental frequency in stutterers and nonstutterers during reading and spontaneous speech. Journal of Fluency Disorders, 8, 125-132.

Shapiro, A. I. (1980). An electromyographic analysis of the fluent and dysfluent utterances of several types of stutterers. Journal of Fluency Disorders, 5, 203-231.

Shattuck-Hufnagel, S. (1979). Speech errors as evidence for a serialorder mechanism in sentence production. In W. E. Cooper \& E. C. T. Walker (Eds.), Sentence processing: Psycholinguistic studies presented to Merrill Garrett (pp. 295-342). Hillsdale, NJ: Erlbaum.

Shatz, N. (1983). Communication. In J. Flavell \& E. Markman (Eds.), Manual of child psychology: Cognitive development (4th ed., Vol. 3, pp. 495-555). New York: Wiley. 
Sheehan, J. G. (1974). Stuttering behavior: A phonetic analysis. Journal of Communication Disorders, 7, 193-212.

Sheehan, J. G., \& Martyn, M. M. (1970). Stuttering and its disappearance. Journal of Speech and Hearing Research, 13, 279-289.

Shine, R. (1980). Direct management of the beginning stutterer. In W. Perkins (Ed.), Seminars in speech, language, and hearing (Vol. 1, pp. 339-350). New York: Thieme-Stratton.

Shipp, T., McGlone, R., \& Morrissey, P. (1972). Some physiological correlates of voice frequency change. In Proceedings of the 7 th International Congress of Phonetic Sciences. The Hague, The Netherlands: Mouton.

Siegel, G. M., Fehst, C. A., Garber, S. R., \& Pick, H. L. Jr. (1980). Delayed auditory feedback with children. Journal of Speech and Hearing Research, 23, 802-813.

Silverman, E. M. (1974). Word position and grammatical function in relation to preschoolers' speech disfluency. Perceptual and Motor Skills, 39, 267-272.

Silverman, F. H., \& Williams, E. D. (1967). Loci of disfluencies in the speech of nonstutterers during oral reading. Journal of Speech and Hearing Research, 10, 790-794.

Slobin, D. I. (1970). Universals of grammatical development in children. In G. B. Flores d'Arcais \& W. J. M. Levelt (Ed.), Advances in psycholinguistics (pp. 174-186). Amsterdam: North Holland.

Smith, B. L. (1978). Temporal aspects of English speech production: A developmental perspective. Journal of Phonetics, 6, 37-67.

Smith, B. L., Hillenbrand, J., Wasowicz, J., \& Preston, J. (1986). Durational characteristics of vocal and subvocal speech: Implications concerning phonological organization and articulatory difficulty. Journal of Phonetics, 14, 265-281.

Soderberg, G. A. (1967). Linguistic factors in stuttering. Journal of Speech and Hearing Research, 10, 801-810.

Sokolov, A. N. (1972). Inner speech and thought. New York: Plenum Press.

Sorokin, V. N. (1975). Analysis of the system of control of speech movements. Biophysics, 20, 725-731.

Starkweather, C. W. (1987). Fluency and stuttering. Englewood Cliffs, NJ: Prentice-Hall

Starkweather, C. W., \& Gottwald, S. R. (1990). The demands and capacities model: II. Clinical applications. Journal of Fluency Disorders, 15, 143-157.

Stathopoulos, E. T., Hoit, J. D., Hixon, T. J., Watson, P. J., \& Solomon, N. P. (1991). Respiratory and laryngeal function during whispering. Journal of Speech and Hearing Research, 34, 761-767.

Stathopoulos, E. T., \& Weismer, G. (1985). An aerodynamic study of stress in children and adults. Journal of Phonetics, 13, 343-355.

Sternberg, S., Monsell, S., Knoll, R. L., \& Wright, C. E. (1980). The latency and duration of rapid movement sequences: Comparisons of speech and typewriting. In R. A. Cole (Ed.), Perception and production of fluent speech (pp. 469-505). Hillsdale, NJ: Erlbaum.

Sutton, S., \& Chase, R. A. (1961). White noise and stuttering. Journal of Speech and Hearing Research, 4, 72.

Thompson, A. H. (1985). A test of the distraction explanation of disfluency modification in stuttering. Journal of Fluency Disorders, 10 , $35-50$.

Till, J. A., Reich, A., Dickey, S., \& Seiber, J. (1983). Phonatory and manual reaction times of stuttering and nonstuttering children. Journal of Speech and Hearing Research, 26, 171-180.

Tornick, G. B., \& Bloodstein, O. (1976). Stuttering and sentence length. Journal of Speech and Hearing Research, 19, 631-654.

Tuller, B., Harris, K. S., \& Kelso, J. A. S. (1982). Stress and rate: Differential transformation of articulation. Journal of the Acoustical Society of America, 71, 1534-1543.

Van Lancker, D., Kreiman, J., \& Bolinger, D. (1988). Anticipatory lengthening. Journal of Phonetics, 16, 339-347.
Van Lieshout, P. H. H. M., Hulstijn, W., \& Peters, H. F. M. (1991). Word size and word complexity: Differences in speech reaction time between stutterers and nonstutterers in a picture and word naming task. In H. F. M. Peters, W. Hulstijn, \& C. W. Starkweather (Eds.), Speech motor control and stuttering (pp. 311-324). New York: Elsevier.

Van Riper, C. (1971). The nature of stuttering. Englewood Cliffs, NJ: Prentice-Hall.

Venkatagiri, H. S. (1980). The relevance of DAF-induced speech disruption to the understanding of stuttering. Journal of Fluency Disorders, 5, 87-98.

Venkatagiri, H. S. (1981). Reaction time for voiced and whispered /a/ in stutterers and nonstutterers. Journal of Fluency Disorders, 6, 265271.

Vilkman, E., Raimo, O. A. I., Ignatius, J., \& Komi, P. V. (1987). On stress production in whispered Finnish. Journal of Phonetics, 15, 157-168.

Viswanath, N. S., \& Rosenfield, D. B. (1991). Intergestural temporal coordination in stutterers. In H. F. M. Peters, W. Hulstijn, \& C. W. Starkweather (Eds.), Speech motor control and stuttering (pp. 347353). New York: Elsevier.

Wall, M. J. (1980). A comparison of the syntax of young stutterers and nonstutterers. Journal of Fluency Disorders, 5, 345-352.

Wall, M. J., Starkweather, C. W., \& Cairns, H. S. (1981). Syntactic influences on stuttering in young child stutterers. Journal of Fluency Disorders, 6, 283-298.

Waters, G. S., Komoda, M. K., \& Arbuckle, T. Y. (1985). The effects of concurrent tasks on reading: Implications for phonological coding. Journal of Memory and Language, 24, 27-45.

Watson, B. C., \& Alfonso, P. J. (1982). A comparison of LRT and VOT values between stutterers and nonstutterers. Journal of Fluency Disorders, 7, 219-241.

Webster, R. L. (1974). Precision Fluency Shaping Program: Speech reconstruction for stutterers. Roanoke, VA: Communications Development.

Webster, W. G. (1985). Neuropsychologic models of stuttering: I. Representation of sequential response mechanisms. Neuropsychologia, 23, 263-267.

Weiner, A. E. (1984). Patterns of vocal fold movement during stuttering. Journal of Fluency Disorders, 9, 31-49.

Weismer, G., \& Ingrisano, D. (1979). Phrase-level timing patterns in English: Effects of emphatic stress location and speaking rate. Journal of Speech and Hearing Research, 22, 516-533.

Wells, G. B. (1979). Effect of sentence structure on stuttering. Journal of Fluency Disorders, 4, 123-129.

Westby, C. E. (1974). Language performance of stuttering and nonstuttering children. Journal of Communication Disorders, 12, 133-145.

Whalen, D. H. (1990). Coarticulation is largely planned. Journal of Phonetics, 18, 3-35.

Wijnen, F. (1988). Spontaneous word fragmentations in children: Evidence for the syllable as a unit in speech production. Journal of Phonetics, 16, 187-202.

Wijnen, F. (1990). The development of sentence planning. Journal of Child Language, 17, 395-399.

Wilding, J., \& White, W. (1985). Impairment of rhyme judgments by silent and overt articulatory suppression. Quarterly Journal of Experimental Psychology, 37a, 95-107.

Williams, D. E., Silverman, F. H., \& Kools, J. A. (1969). Disfluency behavior of elementary-school stutterers and nonstutterers: Loci of instances of disfluency. Journal of Speech and Hearing Research, 11, 308-318.

Wingate, M. E. (1966). Prosody in stuttering adaptation. Journal of Speech and Hearing Research, 9, 550-556. 
Wingate, M. E. (1976). Stuttering: Theory and treatment. New York: Irvington.

Wingate, M. E. (1984). Pause loci in stuttered and normal speech. Journal of Fluency Disorders, 9, 227-235.

Wingate, M. E. (1986). Adaptation, consistency and beyond: I. Limitations and contradictions. Journal of Fluency Disorders, 11, 1-36.

Wingate, M. E. (1988). The structure of stuttering: A psycholinguistic perspective. New York: Springer-Verlag.

Winkler, L. E., \& Ramig, P. (1986). Temporal characteristics in the fluent speech of child stutterers and nonstutterers. Journal of Fluency Disorders, 11, 217-229.

Wode, H. (1980). Grammatical intonation in child language. In L. R. Waugh \& C. H. van Schooneveld (Eds.), The melody of language (pp. 331-345). Baltimore: University Park Press.

Wolk, L. (1990). An investigation of stuttering and phonological diffculties in young children. Unpublished doctoral dissertation, Syracuse University, Syracuse, NY.

Yairi, E. (1983). The onset of stuttering in two- and three-year-old children: A preliminary report. Journal of Speech and Hearing Disorders, 48, 171-177.
Yairi, E., \& Ambrose, N. (1992). A longitudinal study of stuttering in children: A preliminary report. Journal of Speech and Hearing Research, 35, 755-760.

Yairi, E., Ambrose, N. G., \& Niermann, R. (1993). The early months of stuttering: A developmental study. Journal of Speech and Hearing Research, 36, 521-528.

Yeni-Komshian, G., Chase, R. A., \& Mobley, R. L. (1968). The development of auditory and feedback monitoring: II. Delayed auditory feedback studies on the speech of children between two and three years of age. Journal of Speech and Hearing Research, 11, 307-315.

Zimmermann, G. (1980). Articulatory dynamics of fluent utterances of stutterers and nonstutterers. Journal of Speech and Hearing Research, 23, 95-107.

Zimmermann, G., Brown, C., Kelso, J. A. S., Hurtig, R., \& Forrest, K. (1988). The association between acoustic and articulatory events in a delayed auditory feedback paradigm. Journal of Phonetics, 16, 437451.

Received November 30, 1992

Revision received August 1, 1994

Accepted August 2, 1994

\section{MEMBERS OF UNDERREPRESENTED GROUPS: REVIEWERS FOR JOURNAL MANUSCRIPTS WANTED}

If you are interested in reviewing manuscripts for APA joumals, the APA Publications and Communications Board would like to invite your participation. Manuscript reviewers are vital to the publication process. As a reviewer, you would gain valuable experience in publishing. The $P \& C B o a r d$ is particularly interested in encouraging members of underrepresented groups to participate more in this process.

If you are interested in reviewing manuscripts, please write to Leslie Cameron at the address below. Please note the following important points:

- To be selected as a reviewer, you must have published articles in peer-reviewed journals. The experience of publishing provides a reviewer with the basis for preparing a thorough, objective review.

- To select the appropriate reviewers for each manuscript, the editor needs detailed information. Please include with your letter your vita. In your letter, please identify which APA journal you are interested in and describe your area of expertise. Be as specific as possible. For example, "social psychology" is not sufficient-you would need to specify "social cognition" or "attitude change" as well.

- Reviewing a manuscript takes time. If you are selected to review a manuscript, be prepared to invest the necessary time to evaluate the manuscript thoroughly.

Write to Leslie Cameron, Journals Office, American Psychological Association, 750 First Street, NE, Washington, DC 20002-4242. 